\title{
Eradicating HIV-1 infection: seeking to clear a persistent pathogen
}

\author{
Nancie M. Archin ${ }^{1}$, Julia Marsh Sung ${ }^{1}$, Carolina Garrido ${ }^{1}$, Natalia Soriano-Sarabia ${ }^{1}$, and \\ David M. Margolis ${ }^{1,2,3}$ \\ ${ }^{1}$ Department of Medicine, University of North Carolina at Chapel Hill, Chapel Hill, North Carolina \\ 27599, USA \\ ${ }^{2}$ Department of Microbiology and Immunology, University of North Carolina at Chapel Hill, Chapel \\ Hill, North Carolina 27599, USA \\ ${ }^{3}$ Department of Epidemiology, University of North Carolina at Chapel Hill, Chapel Hill, North \\ Carolina 27599, USA
}

\begin{abstract}
Effective antiretroviral therapy (ART) blunts viraemia, which enables HIV-1-infected individuals to control infection and live long, productive lives. However, HIV-1 infection remains incurable owing to the persistence of a viral reservoir that harbours integrated provirus within host cellular DNA. This latent infection is unaffected by ART and hidden from the immune system. Recent studies have focused on the development of therapies to disrupt latency. These efforts unmasked residual viral genomes and highlighted the need to enable the clearance of latently infected cells, perhaps via old and new strategies that improve the HIV-1-specific immune response. In this Review, we explore new approaches to eradicate established HIV-1 infection and avoid the burden of lifelong ART.
\end{abstract}

\begin{abstract}
HIV-1 infection remains incurable owing to the presence of quiescent, replication-competent provirus within a long-lived population of memory $\mathrm{T}$ cells, which are capable of reigniting new rounds of infection if therapy is interrupted. In adults, this latent pool of virus is established within days of infection and is unaffected by the antiviral immune response or by current therapy. HIV-1 preferentially infects activated $\mathrm{CD} 4^{+} \mathrm{T}$ cells, which leads to massive depletion of these cells, as well as the accompanying immune suppression and exhaustion that are characteristic of HIV-1 infection. Infection begins when the HIV-1 envelope (Env) engages the CD4 receptor and a CC-chemokine receptor, usually CCR5 and rarely CXC-chemokine receptor 4 (CXCR4), on the surface of host cells, which leads to fusion of the viral and cellular membranes and thus enables entry of the viral nucleocapsid into the cell. The viral RNA genome is reverse transcribed into proviral double-stranded cDNA, which together with viral and host cellular proteins forms the pre-integration
\end{abstract}


complex (PIC). This complex is imported into the nucleus, where integration of the proviral cDNA into the host genome occurs. In activated $\mathrm{T}$ cells, infection proceeds with the transcription of viral mRNAs, protein production and the generation of new viral particles. In resting $\mathrm{T}$ cells, the provirus may enter quiescence, whereby it exists in a latent state as part of the host gene in which it is integrated.

Several classes of drugs that target the different stages of the viral life cycle have been successfully used in combination antiretroviral therapy (cART) for the treatment of HIV-1 infection. These include: fusion inhibitors and CCR5 co-receptor antagonists, which block viral entry; nucleoside reverse transcriptase inhibitors (NRTIs) and non-nucleoside reverse transcriptase inhibitors (NNR-TIs), which block reverse transcription of the viral genome; integrase inhibitors, which prevent viral integration; and protease inhibitors, which interfere with virion production. However, there are currently no available therapies that target the quiescent integrated form of the virus, and unless this persistent latent infection is eradicated, HIV-1 will remain a chronic viral infection with the enduring potential to cause or spread lethal disease.

Although disappointing, the recent return of viraemia in an infant born to an HIV-1-positive mother (known as the 'Mississippi baby') ${ }^{1}$ more than 2 years after the interruption of ART suggests that individual latently infected cells may remain dormant for considerable periods of time, and perhaps, if the number of latently infected cells is low enough, an antiviral immune response may stringently contain infection. HIV-1 rebounded only several months after stopping treatment in two patients (known as the 'Boston patients') who received bone marrow transplants to treat lymphoma ${ }^{2}$. The shorter time off therapy before rebound in the Boston patients might simply reflect a higher number of latently infected cells in the adult patients and/or the absence of memory $\mathrm{T}$ cells that could harbour quiescent, replicationcompetent provirus in the Mississippi baby at birth. Approaches to disrupt latency or durably enforce latency, in combination with effective therapeutic agents that continuously enhance the immune response to HIV-1 infection, must now be even more seriously considered.

In this Review, we briefly describe the main mechanisms that are involved in the establishment and maintenance of HIV-1 latency and discuss cellular HIV-1 reservoirs, including memory $\mathrm{T}$ cells and their precursor cells, as well as myeloid cells, with a focus on macrophages. We then discuss the current cell and animal models that are available for the study of HIV-1 latency and the proposed strategies to disrupt latent infection and enable clearance of persistently infected cells.

\section{HIV-1 latency}

Latently infected resting memory $\mathrm{CD} 4^{+} \mathrm{T}$ cells are the best characterized reservoirs of HIV-1 infection. These are a small population of cells that, rather than dying from the direct or indirect cytopathic effects that are induced by the virus, persist after infection as longlived cells that harbour integrated HIV-1 DNA in their genomes ${ }^{3}$. This latent reservoir is established within days of acute infection ${ }^{4}$, with continued contributions from active, uncontrolled viraemia in the absence of ART, and although early treatment with ART can 
reduce the size of this pool of infected cells, it cannot prevent the establishment of latent, persistent HIV-1 infection ${ }^{5,6}$.

Infection of resting $\mathrm{CD} 4^{+} \mathrm{T}$ cells is far less efficient than infection of activated cells ${ }^{7-10}$, which express factors that are crucial for HIV-1 transcription. Latency may primarily be established in activated $\mathrm{CD}^{+} \mathrm{T}$ cells that are infected as they transition to the resting memory state ${ }^{11}$. However, recent studies using primary $\mathrm{CD} 4^{+} \mathrm{T}$ cells that are infected with dual-labelled HIV-1 reporter viruses suggest that a small fraction of transcriptionally silent infection occurs directly in activated $\mathrm{CD}^{+} \mathrm{T}$ cells that have not yet transitioned to a resting state ${ }^{12}$. Whether this phenomenon occurs in vivo remains to be determined. HIV-1 persists in resting cells, but is transcriptionally silent and therefore 'hidden' from immune surveillance and unaffected by $\mathrm{ART}^{4,13}$. However, as latent HIV-1 still remains replicationcompetent and has the ability to re-emerge when therapy is interrupted, it poses a considerable barrier to the eradication of HIV-1. Furthermore, there are currently no known cellular biomarkers that distinguish latently infected cells from uninfected cells, although it has been shown that some latently infected resting $\mathrm{CD}^{+} \mathrm{T}$ cells express high levels of CD2 (REF. 14).

Despite some evidence to the contrary ${ }^{15,16}$, ongoing viral replication has been suggested to contribute to the persistence of HIV-1 infection even in the presence of therapy. Sensitive assays have detected trace levels of viraemia in many ART-treated patients ${ }^{17,18}$. This phenomenon seems to be the result of continuing viral expression from cells that were infected before the implementation of ART. However, it has been suggested that ongoing viral replication in a pro-inflammatory environment within lymphoid tissue contributes to the maintenance of persistent infection. Evidence for ongoing viral replication has previously been reported ${ }^{19-21}$ and cell-to-cell spread of HIV-1 was recently proposed as a mechanism that facilitates ongoing replication despite $\mathrm{ART}^{22}$; however, these findings have been challenged ${ }^{23-25}$.

The adequacy of ART is an area of continued controversy. Treatment intensification with the integrase inhibitor raltegravir had no effect on low-level viraemia, but it was associated with an increase in the generation of circular HIV-1 DNA episomes that contain two copies of the two-long terminal repeat circles (2-LTR circles) ${ }^{21,26}$ and a reduction in the levels of recoverable HIV-1 (REF. 27). However, these findings were not seen in all raltegravir intensification studies ${ }^{28}$.

Another recent study observed persistent HIV-1 RNA expression in tissues (although after only 6 months of therapy) and low levels of some antiretroviral drugs in some tissues ${ }^{29}$. However, it has been noted that, although intracellular active nucleotide metabolites remain stably inside cells during processing ${ }^{30}$, parent drugs quickly diffuse out of cells ${ }^{31}$, which makes it difficult to obtain accurate measurements of active drug levels. The amount of NNRTIs, protease inhibitors or integrase strand transfer inhibitors (INSTIs) that are lost from cells during isolation is currently unknown. Furthermore, the fact that low-level plasma viraemia remained unaffected following the intensification of therapy and the lack of genetic evolution of plasma virus ${ }^{20,32-34,16}$ leaves many in this field of research convinced that 
residual viral replication may not be involved in the maintenance of persistent HIV-1 infection.

Homeostatic proliferation of latently infected cells may alternatively, or additionally, contribute to the maintenance of this cell pool ${ }^{35,36}$. Recent studies have shown an enrichment of HIV-1 DNA integrated in, or near to, host genes that are associated with cell cycle control. These findings suggest an alternative mechanism for proviral persistence, whereby the integration of HIV-1 into such sites could lead to proliferation of the latently infected cells ${ }^{37,38}$. However, further experiments are necessary to fully examine this theory, and it is possible that the observed results were reflective of accumulated, defective proviral DNA rather than truly replication-competent virus ${ }^{39}$. Like host gene expression, the latency of integrated, proviral DNA is regulated by multiple cellular mechanisms, including epigenetic transcriptional silencing, the availability or deficiency of key host factors and transcriptional interference (reviewed in detail in REF. 38). Briefly, host transcription factors, including nuclear factor- $\kappa \mathrm{B}(\mathrm{NF}-\kappa \mathrm{B})$, nuclear factor of activated $\mathrm{T}$ cells (NFAT), AP1 and SP1, are sequestered in the cytoplasm in resting cells and thus do not promote HIV-1 transcription until an appropriate cellular activation signal is transmitted (FIG. 1). HIV-1 integration into the host genome preferentially occurs within introns of actively transcribed host genes ${ }^{40-42}$. Multiple distinct and complementary mechanisms contribute to the establishment of latent proviral infection (FIG. 1).

Epigenetic modifications are involved in the initial establishment and subsequent enforcement of transcriptional silencing of the provirus. Independent of the site of integration, the viral 5' LTR is occupied by two specific nucleosomes - Nuc-0 and Nuc-1 (REF. 43) - that can be marked by repressive post-translational histone modifications ${ }^{44,45}$. Histone deacetylation is associated with transcriptional repression of the HIV-1 promoter, and inhibition of histone deacetylases (HDACs) reactivates latent HIV-1 (REF. 46). Histone methyltransferases (HMTs), such as EZH2, G9a and SUV39H1, have also been suggested to contribute to latency in $\mathrm{T}$ cells ${ }^{45,47}$. These chromatin marks create an environment that favours the recruitment of additional factors and complexes that antagonize proviral gene expression.

An additional, or complementary, mechanism to suppress the expression of the integrated provirus is transcriptional interference, which involves the integration of the provirus in the same orientation but down-stream of an actively transcribed host gene (known as promoter occlusion) or the integration provirus in the opposite orientation relative to the host gene (known as convergent transcription) (FIG. 1). Transcriptional elongation is suppressed by sequestration of positive transcription elongation factor $\mathrm{b}$ (p-TEFb), which comprises cyclindependent kinase 9 (CDK9) and cyclin T1 (REFS 48,49) and associates with the HEXIM17SK small nuclear RNA (snRNA) regulatory complex. CDK9 is constitutively expressed in resting cells in an inactive dephosphorylated form ${ }^{50}$. HIV-1 Tat recruits p-TEFb to the viral promoter, where active CDK9 can promote transcriptional elongation ${ }^{46}$ (FIG. 1).

Finally, microRNAs (miRNAs) may contribute to latency, although their specific role has not yet been fully established (reviewed in REF. 51). The factors and steps that lead to complete HIV-1 transcription after reactivation have recently been reviewed ${ }^{46}$. 


\section{Cellular reservoirs of HIV-1}

It is crucial to identify and fully characterize all reservoirs of persistent HIV-1 infection so that specific therapies can be devised. The nature of these reservoirs is still a subject of controversy. To meet the criteria of a long-lived, latent reservoir of HIV-1 infection, an infected cell population must persist for months, restrict viral expression to the extent that viral antigen is not presented and harbour quiescent virus that is replication-competent following reactivation.

\section{Memory $\mathrm{CD4}^{+} \mathrm{T}$ cells}

HIV-1 DNA is primarily detected in two subsets of memory CD4 ${ }^{+} \mathrm{T}$ cells: central memory $\mathrm{CD}^{+}{ }^{+} \mathrm{T}$ cells $\left(\mathrm{T}_{\mathrm{CM}}\right.$ cells) and transitional memory $\mathrm{CD} 4^{+} \mathrm{T}$ cells $\left(\mathrm{T}_{\mathrm{TM}} \text { cells }\right)^{35} \cdot \mathrm{T}_{\mathrm{TM}}$ cells are characterized by the expression of CD27 but lack expression of the lymph node homing receptor CCR7, whereas $\mathrm{T}_{\mathrm{CM}} \mathrm{CD}^{+} \mathrm{T}$ cells express both CD27 and CCR7. The frequency of infection of $\mathrm{T}_{\mathrm{CM}}$ cells is associated with the presence of human leukocyte antigen-B27 (HLA-B27) and HLA-B57, which have been shown to have a protective role in long-term non-progressors ${ }^{52}$.

Interleukin-7 (IL-7)-mediated homeostatic proliferation was reported to be the main mechanism that maintains latency in $\mathrm{T}_{\mathrm{TM}}$ cells in patients with low CD4 counts, whereas antigen-driven $\mathrm{T}$ cell receptor (TCR) activation maintains the reservoir in $\mathrm{T}_{\mathrm{CM}}$ cells ${ }^{35}$, although in this case the hypothesis holds that antigen-driven activation must not be sufficiently strong to induce reactivation of HIV-1 from these cells ${ }^{36}$. Another recent study found that HIV-1 DNA and RNA levels were high among $\mathrm{T}_{\mathrm{TM}}$ cells in patients who are early in the course of infection ${ }^{53}$. However, preliminary analysis of the frequency of replication-competent virus by a quantitative viral outgrowth assay (QVOA) (BOX 1) in $\mathrm{T}_{\mathrm{CM}}$ and $\mathrm{T}_{\mathrm{TM}}$ cells showed that $\mathrm{T}_{\mathrm{TM}}$ cells are major contributors to the HIV-1 reservoir in only a minority of the patients studied, and in those patients, infection of $\mathrm{T}_{\mathrm{TM}}$ cells does not seem to persist as it does in $\mathrm{T}_{\mathrm{CM}}$ cells ${ }^{54,187}$. Owing to the challenges that are inherent in comparing measurements of rare events in small populations of cells, further longitudinal analyses are needed to clarify whether $\mathrm{T}_{\mathrm{TM}}$ cells constitute a durable and clinically significant reservoir in patients who are successfully treated with ART and who have normal CD4 counts.

\section{Box 1}

\section{Assays of persistent infection}

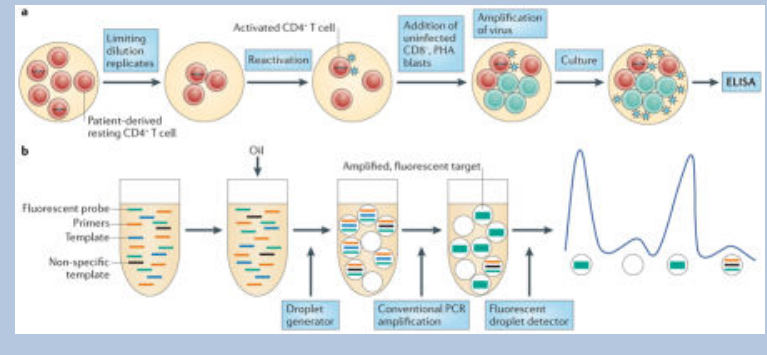

Nat Rev Microbiol. Author manuscript; available in PMC 2015 November 01. 
The quantitative viral outgrowth assay (QVOA) $)^{174,175}$ measures rare replicationcompetent but latent HIV-1 (see the figure, part a). Highly purified latently infected resting $\mathrm{CD}^{+} \mathrm{T}$ cells are plated in a serial dilution and are maximally activated to reverse latency. Activated peripheral blood mononuclear cells (PBMCs) that are isolated from uninfected donors are added to propagate the virus. The QVOA is costly, slow and unavoidably requires many cells. Further, it may under-represent the true frequency of latent infection, as some 'non-induced' proviruses are not recovered following the single stimulation that is used in this assay ${ }^{138}$. Improvements to the QVOA are being sought, but it currently remains the most reproducible and reliable method to measure HIV-1 latency and assess eradication strategies ${ }^{176}$.

Quantitative PCR (qPCR) measures total or integrated HIV-1 DNA, or cell-associated RNA (caRNA), in cells and is the most commonly used method to quantify persistent HIV-1 infection ${ }^{177}$. Two-long terminal repeat (2-LTR) circles may be a marker for lowlevel replication in patients on antiretroviral therapy (ART), but this is controversial ${ }^{177}$. The caRNA may be a useful measure of residual virus expression or of the frequency of latent infection ${ }^{178}$. As caRNA indiscriminately measures functional, defective or abortive viral RNA, levels of caRNA in patients treated with ART may not reliably correlate with the frequency of replication-competent HIV-1 (REF. 178). Nevertheless, changes in caRNA levels can enable the assessment of anti-latency interventions in vivo ${ }^{130,132,133}$.

Single-copy assays of plasma HIV-1 RNA, which are an ultrasensitive, well-established method to quantify low-level plasma viraemia in patients receiving ART, might contribute to monitoring eradication therapies ${ }^{179}$. Droplet digital PCR (ddPCR) (see the figure, part b) is under development to improve assay precision for low levels of HIV-1 DNA and caRNA ${ }^{180-182}$. The droplet technique enables the sample and PCR reaction mixture to be partitioned into thousands of individual droplets such that each contains a single copy of the target, which facilitates precise endpoint quantification.

However, PCR-based assays cannot distinguish defective proviruses from intact ones ${ }^{183,184}$. HIV-1 DNA forms are detected about 300 -fold more often than replicationcompetent HIV-1 in QVOAs ${ }^{185}$. ELISA, enzyme-linked immunosorbent assay; PHA, phytohaemagglutinin.

\section{Other T cell subsets}

In addition to the well-established memory $\mathrm{CD} 4^{+} \mathrm{T}$ cell reservoir, it is possible that less differentiated populations of $\mathrm{CD}^{+} \mathrm{T}$ cells function as long-term, cellular reservoirs. The role of $\mathrm{CD} 34^{+}$haematopoietic progenitors as additional reservoirs for HIV-1 has been controversial for many years ${ }^{55}$; for example, HIV-1 infection and the establishment of latent infection in $\mathrm{CD}_{3} 4^{+}$haematopoietic progenitor cells in patients on ART have been reported $^{56,57}$, but these studies were not confirmed by others ${ }^{58,59}$. If progenitor cells are durably latently infected, they could be a source of persistent HIV-1 production when these cells go through proliferative cycles. However, the initial description of HIV-1 infection in these haematopoietic stem and progenitor cells found that proliferation resulted in the death of these infected cells in vitro ${ }^{56,57}$. Therefore, although this reservoir might be established before therapy, it would be expected to decay over time during treatment. 
In addition to memory $\mathrm{CD} 4^{+} \mathrm{T}$ cells, latent infection of naive $\mathrm{CD} 4^{+} \mathrm{T}$ cells in patients on ART has also been shown, although this event seems to occur with even lower frequency 35,60 . A recent study reported that $\mathrm{CD} 4^{+}$memory stem cells ( $\mathrm{T}_{\mathrm{SCM}}$ cells) constitute a novel HIV-1 reservoir that may not be large but that seems to be stable over time $^{61}$. $\mathrm{T}_{\mathrm{SCM}}$ cells are a population with characteristics of stem cells: they have a less differentiated phenotype and are reported to be extremely long-lived ${ }^{62,63}$. The contribution of these $\mathrm{T}_{\mathrm{SCM}}$ cells to the total HIV-1 reservoir, which is reported to be less than $10 \%$, may be especially relevant in patients with small $\mathrm{T}_{\mathrm{CM}}$ cell reservoirs.

Preliminary work also detected the presence of replication-competent virus and HIV-1 DNA in $\gamma \delta \mathrm{T}$ cells, which are a subset of $\mathrm{CD} 3^{+} \mathrm{T}$ lymphocytes that harbour alternative TCRs formed by $\gamma$-chains and $\delta$-chains ${ }^{54}$. The biology of $\gamma \delta \mathrm{T}$ cells differs from conventional $\alpha \beta \mathrm{T}$ cells; for example, $\gamma \delta$ T cells do not recognize peptide antigens but rather recognize lipid antigens in a major histocompatibility complex (MHC)-unrestricted manner ${ }^{64-68}$. These differences in the signalling and activation of $\gamma \delta \mathrm{T}$ cells suggests the induction of latent HIV-1 provirus in $\gamma \delta \mathrm{T}$ cells may have different requirements.

\section{Persistent infection of macrophages}

Enduring infection of macrophages, their precursors or other myeloid lineage cells, such as dendritic cells, has long been a concern. Infection of macrophages, with the potential for both high-level viral production in the presence of macrophage-derived pro-inflammatory cytokines, and the potential for durable viral production, given the resistance of macrophages to viral cytopathicity in vitro, was first demonstrated nearly 30 years ago ${ }^{69-71}$. HIV-1 has been recovered from the circulating monocyte pool of patients treated with $\mathrm{ART}^{72}$, but the durability of this reservoir has not been carefully measured as it has in memory $\mathrm{T}$ cells. Brain astrocytes, microglia and other related cellular lineages in the brain have been shown to support a restricted infection that could persist despite $\mathrm{ART}^{73,74}$. However, even after years of study, a clear demonstration that macrophages and these other related cells are truly latent viral reservoirs is lacking. Such cells have not fulfilled the strict definition of latency, which is the recovery of cells from a patient or animal on durable, suppressive ART that produce virions only following activation.

However, although definitive proof is lacking, several characteristics of these cell types would seem to make them ideal reservoirs for long-term infection. The long-standing view of macrophages as terminal cells in the myeloid differentiation pathway has recently changed, and the ability of macrophages to self-renew and repopulate tissues has been appreciated $^{75}$. This presents the possibility that, like T cells, infected macrophage populations could persist despite low-level virion production and clearance of some infected cells, if at least one-half of the dividing macrophages escaped viral cytolysis. It is crucial to be clear about the difference in persistence of HIV-1 infection in myeloid cells - in which cells may survive for long periods of time while viral genomes are in a state of non-latency and low-level HIV-1 expression - and true virological latency in $\mathrm{CD}^{+} \mathrm{T}$ cells - in which the viral genomes must be mostly silenced, without any appreciable expression of viral proteins. This distinction results in key differences in methods to detect persistent infection in myeloid cells and to eliminate persistent infection (BOX 1); for example, the challenge of 
disrupting latent infection in $\mathrm{CD} 4^{+} \mathrm{T}$ cells may be of little relevance in macrophages if productive infection already persists owing to very low-level viral expression. If this is the case, we would instead need to develop interventions to assist in the clearance of persistently infected myeloid cells.

Recent advances in the implementation of fully effective ART in the non-human primate (NHP) SIV model system (see below) offer hope that this controversy will soon be resolved $^{76}$, as extensive and conclusive tissue sampling of optimally treated animals should be possible. In addition, recently developed humanized mouse models of latent HIV-1 infection will address this question in the context of the human virus in human cells ${ }^{77}$. The flexibility of the humanized BLT (bone marrow-liver-thymus) mouse has recently enabled the generation of animals that have macrophages but that do not have $\mathrm{T}$ cells ${ }^{78}$. If infection persists in this model system in the presence of continuous therapy, this would provide definitive proof of a latent reservoir in macrophages.

\section{Model systems of HIV-1 latency}

No model can fully recapitulate the complexities of the latent reservoir in vivo. However, as clinical trials will always necessarily limit therapeutic interventions to those with reasonable expectations of safety and efficacy, models will continue to have a crucial role in HIV-1 eradication research (FIG. 2).

\section{Cell models of latency}

Cell models have been particularly useful for understanding the basic mechanisms that are involved in establishing and maintaining latency as well as for the initial screening of latency-reactivating agents ${ }^{79}$ (FIG. $2 \mathrm{a}-\mathrm{c}$ ). Although resting memory $\mathrm{CD} 4^{+} \mathrm{T}$ cells constitute the major latent HIV-1 reservoir in humans, studies using these cells are limited by the very low frequency of infection ${ }^{80}$. Primary cell models aim to overcome these limitations by establishing latent HIV-1 infection in $\mathrm{CD}^{+} \mathrm{T}$ cells that have been isolated from HIV-1negative donors at a higher frequency. As such cells are not immortalized or clonal, primary cell models might offer a more physiologically relevant representation of latency than cell lines, and their responsiveness to stimuli might be more representative of in vivo biology. Several cell models are currently being used ${ }^{81-88}$ (reviewed in REFS 89,90), and there are important differences in the cell subsets, viral strains and mechanisms that are used to establish latency ${ }^{89,90}$ (TABLE 1). A careful comparison of latent HIV-1 reactivation by different stimuli across multiple primary cell models revealed diverse responses to the same stimuli. In addition, such responses are not uniformly consistent with results obtained using QVOA in resting $\mathrm{CD}^{+} \mathrm{T}$ cells that have been isolated from aviraemic patients infected with HIV-1 (REF. 89) (BOX 1). For example, HIV-1 expression can be induced in J-lat clones and primary cells from patients by HDAC inhibitors, whereas several primary cell models of latency are resistant to the effects of HDAC inhibitors. Given the complexity and diversity of latency in vivo and the varying responses of these models, information from primary cell models may be expanded by evaluating responses in more than one model ${ }^{91}$. 


\section{Humanized mouse models}

The establishment of successful mouse models of latent HIV-1 infection required substantial adaptation of the host (FIG. 2d,e), as mice are not naturally susceptible to HIV-1 infection (reviewed in REF. 92). The development of the humanized BLT mouse ${ }^{77,93-97}$, which is characterized by a complete reconstitution of human immune cells, including full mucosal immunity, has greatly increased the ability to study the distribution of infection and latency ${ }^{77,96,98-102}$ (FIG. 2e). A recent study ${ }^{102}$ extensively characterized sites of residual active viraemia during ART in blood and multiple tissues and found reduced, but detectable, residual viral RNA expression in all tissues (especially lymphoid tissues), despite adequate tissue drug concentrations. The humanized BLT mouse model also enables manipulation of the immune system to generate HIV-1-resistant cells and/or an enhanced immune response via transgenic or short hairpin-mediated modifications of $\mathrm{CD} 34^{+}$stem cells before transplantation ${ }^{103,104}$. Further adaptations of humanized mice that are aimed at isolating discrete cell populations of interest are currently being developed; for example, using a novel $\mathrm{T}$ cell-only humanized mouse model ${ }^{105}$, a recent study showed that latency is established in resting $\mathrm{CD} 4^{+} \mathrm{T}$ cells despite the absence of monocytes, macrophages, $\mathrm{B}$ cells and dendritic cells.

\section{NHP models}

Animal models are well-suited for the study of the anatomical and cellular distribution of latent infection in the setting of ART treatment, as well as for the evaluation of certain highrisk treatments that would be unethical for initial human trials (FIG. 2f). SIV and recombinant viral strains derived from SIV (such as RT-SHIV and SHIV) cause a pathogenic disease course in Asian macaques that is similar to that of HIV-1 in humans, and treatment with ART results in plasma viral decay ${ }^{106-110}$ and the establishment of inducible replication-competent virus in resting $\mathrm{CD}^{+}{ }^{+} \mathrm{T}$ cells ${ }^{106,111}$. Neurotropic strains of SIV, such as SIV/17E-Fr, have also been used to establish models of central nervous system (CNS) disease during infection and ART ${ }^{107,112-114}$. These studies have shown the establishment of HIV-1 DNA early in the course of infection, despite the initiation of ART during acute infection, although the specific cellular reservoirs within the brain tissue were not delineated and studies were limited by reliance on evaluation of HIV-1 DNA rather than replicationcompetent virus. The development and application of recombinant RT-SHIV ${ }^{115}$ has provided further approaches to characterize latent reservoirs following treatment with clinically relevant ART regimens ${ }^{116,117}$. RT-SHIV-infected macaques that were treated with ART were found to have a widespread distribution of both viral RNA and DNA, especially in the gut and lymphoid tissues ${ }^{116}$.

The SIV-macaque model was also key to understanding the role of the immune response in controlling HIV-1 infection ${ }^{118}$. Recent studies using a rhesus cytomegalovirus (CMV) vector vaccine in macaques, followed by infection with SIV, led to suppression of viraemia below the limit of detection in 50\% of animals ${ }^{119,120}$. Although correlates and mechanisms of protection are still under investigation, interestingly, the rhesus CMV vector induced a non-canonical, MHC II-restricted $\mathrm{CD} 8^{+} \mathrm{T}$ cell response. It is unclear how directly translatable the magnitude of the results will be in human trials, especially for patients who started ART during chronic therapy. Autologous pre-infected CD34 ${ }^{+}$haematopoietic stem 
cell (HSC) transplants have also been used in SIV-infected macaques as a tool to investigate the potential contribution of non-haematopoietic reservoirs to the persistence of HIV-1 (REF. 121). In addition, transplantation of autologous HSCs that were genetically engineered to be HIV-1-resistant has also been explored as a therapeutic strategy in macaques ${ }^{122}$. However, although similar to humans, the macaque immune response to SIV is distinct, and results that are obtained in macaques might not translate to the human system.

\section{Strategies to disrupt latent infection}

Several modalities to target the latent reservoir have been proposed. These interventions aim at inducing proviral expression to enable clearance of the virus and infected cells ${ }^{123}$ (FIG. 1; TABLE 2). Early attempts to reactivate virus production via global $\mathrm{T}$ cell activation using OKT3 and IL-2 in combination led to toxic levels of immune activation, and thus current strategies focus on reactivating the virus in the absence of $\mathrm{T}$ cell activation ${ }^{124}$. However, most of these approaches have been validated only in cell line models of HIV-1 latency, and only a few have been tested in resting $\mathrm{CD}^{+} \mathrm{T}$ cells that have been isolated from aviraemic patients $^{51,91,125-128}$.

Many primary cell models of latency have recently been developed, and the responses of these models to a panel of reagents that are known to induce LTR expression were compared in a comprehensive study ${ }^{89}$. Although some of these models reflect the responses that have been obtained in resting $\mathrm{CD} 4^{+} \mathrm{T}$ cells that have been isolated from aviraemic patients, none precisely reflects the responses of cells from patients to every type of anti-latency modality that has been tested ${ }^{89}$. Furthermore, a recent report using resting $\mathrm{CD} 4^{+} \mathrm{T}$ cells from aviraemic patients showed that latency-reversing agents, such as HDAC inhibitors, only weakly induced HIV-1 transcription ${ }^{129}$, but it is difficult to directly compare the precise assays and conditions that were used in this study to those measured in a clinical trial ${ }^{130}$. Therefore, in primary polyclonal cell models of HIV-1 latency, cell-specific factors present a challenge to the use of ex vivo cell systems for the validation of potential anti-latency approaches, and even the research assays that are used to evaluate cells from patients still lack a relevant clinical endpoint (that is, depletion of latent infection) to validate the relevance of the effects measured.

Nevertheless, the use of small-molecule inhibitors that target HDACs and induce transcription at the HIV-1 LTR remains the most well-characterized strategy to purge latent HIV-1 (REF. 131), and several HDAC inhibitors have advanced into clinical trials ${ }^{132-134}$ (TABLE 2). A single $400 \mathrm{mg}$ dose of the class I HDAC inhibitor vorinostat, can disrupt latency in humans, as measured by the expression of HIV-1 RNA in isolated resting CD4 ${ }^{+} \mathrm{T}$ cells ${ }^{130}$. The finding of increased levels of HIV-1 RNA transcription on the first day of therapy has been replicated in a study in which 14 daily doses of vorinostat were administered $^{133}$ and in another study with the HDAC inhibitor, panobinostat, which was administered three times a week for 4 weeks with weekly off-drug intervals ${ }^{132}$. These studies measured HIV-1 RNA in total $\mathrm{CD}^{+}{ }^{+} \mathrm{T}$ cells rather than in isolated resting $\mathrm{CD}^{+} \mathrm{T}$ cells. In addition, these studies found that, compared with a single baseline pre-dose measurement, the levels of unspliced HIV-1 RNA within total CD4 ${ }^{+} \mathrm{T}$ cells is increased 
throughout the dosing period and is still increased 84 days after the initial dose of the HDAC inhibitor.

However, a subsequent follow-up study observed a dampened response to vorinostat following administration of multiple daily doses to patients who responded to the single dose ${ }^{135}$. Preliminary gene expression analysis of resting $\mathrm{CD}^{+} \mathrm{T}$ cells treated ex vivo with a single dose of vorinostat shows a complex multiphasic cascade of host gene expression (D.M.M., unpublished observations). Furthermore, dose-response measurements in patients who received multiple doses of vorinostat showed an exposure-effect relationship with clockwise hysteresis (that is, the response to the initial dose was higher than the response to the subsequent doses), which is consistent with tolerance to vorinostat exposure ${ }^{136}$. Taken together, these results suggest that further understanding of the kinetics of the effects of vorinostat on a crucial subset of host genes - perhaps those that maintain repression of HIV-1 transcription - may be necessary to design a dosing regimen that can lead to effective and durable induction of latent HIV-1 genome expression.

Reactivation of HIV-1 expression by itself may not lead to reservoir clearance, and whether virion production is necessary to achieve viral clearance has not been proven. It is plausible that any viral antigen that is expressed by a latently infected cell that has been stimulated may be sufficient for natural killer cell- or cytotoxic T lymphocyte (CTL)-mediated clearance ${ }^{137}$. Clinical trials to test this hypothesis are in the planning stage.

Successful strategies to disrupt latency are likely to include cycles of combination therapy that target distinct mechanisms that maintain latency. As shown in recent work ${ }^{138}$, about $10 \%$ of integrated provirus that does not express detectable HIV-1 RNA following a single round of maximal mitogen stimulation may still be fully replication competent, which suggests that more than a single round of in vivo $\mathrm{T}$ cell stimulation will be required to purge the reservoir.

A combinatorial effect of drugs that inhibit HDACs or HMTs, or that induce protein kinase $\mathrm{C}$ isoforms (to induce NF- $\mathrm{kB}$-mediated LTR transcription), have been described in various transformed cell line systems, but how these results will be successfully translated to implementation in vivo is unclear ${ }^{139-142}$. Synergistic combination drug therapy to target latent provirus is difficult to define and measure. Synergy of multiple drugs that target different mechanisms of latency might induce the expression of a greater proportion of latent proviruses or induce expression to a greater extent, which might lead to the death of infected cells or improve the recognition and clearance of infected cells by the immune system. However, the level of proviral expression that will result in cell death or in immune recognition and clearance has yet to be determined. It seems likely that a highly potent induction of the latent virus could result in host toxicity and/or levels of viral expression that could not be contained by ongoing ART. Synergy has often been described as a combined effect that is greater than the sum of the effect of two separate modalities. However, a recent study cautioned against this simplistic definition of synergy, given the complexity of biological systems, and suggested the use of the Chou-Talalay method ${ }^{143}$ to more accurately measure the effects of multiple antiretroviral drug therapy. 
cART suppresses plasma viraemia and controls HIV-1 infection by targeting specific viral enzymes and inhibiting fusion and entry, which enabled the development of well-established laboratory models that predict clinical effects. Combination cancer chemotherapy and immunotherapy have only recently been successfully used after many years of intense research. Lessons from both fields may offer insights into how to proceed with combinatorial latency eradication approaches.

An important area for future study is to establish validated cell and animal model systems that can reliably evaluate combinatorial approaches to disrupt HIV-1 latency. An initial study in the humanized mouse model that examined the effect of a novel immunotoxin that recognized and killed cells expressing HIV-1 Env when added to an antiretroviral drug regimen has recently been reported ${ }^{102}$, but the impact of interventions on latent persistent infection has not yet been successfully tested in this model or in NHPs. Many questions arise in such investigations, such as: which response parameters are predictive of disruption of latency in vivo; what is the temporal manner in which reagents are delivered, in series or in parallel, in what order and for what duration; do these reagents access all the relevant tissue compartments in which latently infected cells reside; do these reagents induce clearance without other interventions; if interventions work via a host cell response (for example, vaccines, antibodies or cytokines; see below), do host-targeted anti-latency therapies affect such adjunctive therapies?

\section{Clearing persistently infected cells}

The induction of latent proviral expression may not be sufficient to clear latently infected cells by viral cytopathic effects alone ${ }^{144}$, but the expression of HIV-1 antigens may enable the immune system to identify latently infected cells. However, continuous antigenic stimulation during HIV-1 infection leads to chronic immune activation and immune exhaustion, and therefore HIV-1-specific effector cells are depleted or dysfunctional as they lose antiviral function and proliferative capacity ${ }^{145}$. An effective eradication strategy is likely to require interventions to improve the HIV-1-specific immune response (FIG. 3).

\section{Therapeutic vaccines}

HIV-1 infection compromises T cell effector function and also provokes B cell exhaustion, which may result in an inadequate antibody response ${ }^{146}$. The objective of a therapeutic vaccine is to enhance the immune response against infection using a controlled in vivo exposure to HIV-1 antigens. The rebound viraemia that was observed in the Mississippi baby after 27 months of ART interruption poignantly illustrates the need for a robust, durable antiviral immune response that eliminates every single infected cell. Mutations that confer resistance to CTLs are prevalent in the latent reservoir ${ }^{147,148}$ and present a formidable but not insurmountable challenge that might be overcome in the setting of a small reservoir in which the restriction of viral escape is enforced by ART, by a vaccine that targets carefully chosen conserved, autologous or polyclonal epitopes, or by novel strategies.

Several therapeutic HIV-1 vaccines have been tested, including whole inactivated virus, recombinant proteins or viruses, DNA vectors or dendritic cell presentation of autologous antigens (reviewed in REF. 149) (FIG. 3a). Some vaccines improved HIV-1-specific 
immune responses ${ }^{150,151}$, but none so far has enabled sustained interruption of ART, and this metric may be inappropriately stringent for the goal of eradication in the setting of ongoing ART and anti-latency therapies. Furthermore, such vaccines have not yet been tested for the most relevant factors in the context of eradication strategies, such as: the recognition of relevant epitopes in the context of infection emerging from the latent state; a reduction of low-level viraemia that persists during ART; or a decrease in the frequency of latently infected cells. These aspects should be considered in future studies.

\section{Cell-based therapies}

One potential strategy to clear persistently infected cells is the adoptive transfer of HIV-1specific CTLs ${ }^{152}$. In a primary cell model of latency, Gag-stimulated CTLs are much more effective at clearing reactivated HIV-1-infected cells than freshly isolated CD8 ${ }^{+} \mathrm{T}$ cells ${ }^{144}$. Preliminary work shows that expansion of $\mathrm{T}$ cells against multiple overlapping peptides from different HIV-1 antigens enables increased clearance of reactivated latently infected cells ex vivo ${ }^{153}$.

Other cytotoxic immune cells are of interest owing to their potential to clear infected cells, in some cases using mechanisms that complement the action of CTLs ${ }^{154}$. Natural killer cells, lymphokine-activated killer (LAK) cells ${ }^{155}$ and $\gamma \delta$ T cells ${ }^{156}$ are also very effective at eliminating virally infected targets. However, similarly to CTLs, these immune effectors require priming for optimal function. In oncology applications, effector cells are primed with cytokines, such as IL-15, that have been administered directly in vivo or used ex vivo for activation before reinfusion ${ }^{157,158}$. Monoclonal antibodies could also improve effector cell engagement with the infected targets and, in the case of natural killer cells, mediate targeted lysis via antibody-dependent cellular cytotoxicity (ADCC) ${ }^{159,160}$ (FIG. 3b).

\section{Gene therapy}

Effector cells can also be genetically engineered to increase their efficiency and redirect them to the desired targets. Such approaches have been pioneered in oncology, whereby $\mathrm{T}$ cells are genetically modified to express chimeric antigen receptors (CARs) with improved antigen specificity ${ }^{161}$. This strategy has been adapted to target HIV-1 by genetically modifying peripheral blood cells with a molecularly cloned TCR that redirects cells to viral antigens (FIG. 3c). Encouraging results were shown in a study in which a TCR from a patient who had a sustained and robust CTL response against the HIV-1 p17 Gag-derived antigen SL9 was cloned and expressed in primary $\mathrm{CD} 8^{+}$cells ${ }^{162}$, and a Phase 1 clinical trial is being carried out (clinicaltrials.gov identifier NCT00991224). Nonetheless, this novel and promising tool should be carefully explored owing to potential off-target toxicities ${ }^{163}$. Although such approaches might be too resource-intensive to be implemented on a global scale, they may provide proof-of-concept that could lead to strategies that are appropriate for global implementation.

\section{Reversing immune exhaustion}

Chronic HIV-1 infection leads to the upregulation of inhibitory co-receptors, such as PD-1, on T cells ${ }^{164}$ and cytotoxic T lymphocyte-associated protein 4 (CTLA4) (REF. 165), which are cellular markers of immune exhaustion ${ }^{91}$ that have an important role in the ineffective 
viral immune response. Blockade of the PD-1 pathway reverses this state of exhaustion and restores the ability of T cells to inhibit HIV-1 replication in vitro and in vivo in animal models ${ }^{166}$ and thus presents a promising potential therapeutic intervention (FIG. 3a) that will soon be tested in a clinical trial (clinicaltrials.gov identifier NCT02028403).

\section{Immunotoxins and radioimmunotherapy}

Immunotoxins are bifunctional chimeric proteins that consist of a targeting portion, such as an antibody or a ligand, and a toxin effector domain ${ }^{167}$. Initial clinical trials using immunotoxins did not have a sustained impact on immunological or clinical endpoints ${ }^{168}$, perhaps owing to the lack of support from an ART regimen. The addition of the immunotoxin 3B3-PE38 (REF. 169) to ongoing ART was recently shown to reduce tissue levels of HIV-1 RNA in a humanized mouse model ${ }^{102}$ to several logs below the levels that are seen with ART alone (FIG. 3d). Moreover, radioimmunotherapy using radiolabelled antibodies that target the HIV-1 envelope proteins gp120 and gp41 led to a depletion of chronically HIV-1-infected cells in a severe combined immunodeficiency-peripheral blood lymphocyte (SCID-PBL) mouse model that does not allow viraemia and viral replication ${ }^{170}$. However such short-term animal studies cannot yet address potential off-target effects, such as hepatotoxicity, that are seen with older immunotoxins ${ }^{168}$.

\section{Conclusions}

Efforts to develop therapies that could eradicate HIV-1 infection or achieve a durable remission of viraemia in the absence of ART have recently accelerated and expanded. Although this initial period of renewed effort has been marked by much progress and enthusiasm, both the scientific and the patient community must be prepared for the prolonged effort that will be required to overcome both the expected and the unforeseen challenges ahead. First, and perhaps most daunting, is the need to target latency within specific cellular reservoirs to disrupt viral quiescence so that residual infection can be cleared (FIG. 4). An alternative strategy would be to permanently repress HIV-1 gene expression or to directly destroy the genome. Recent advances with gene-modifying technologies such as zinc-finger nucleases, TALENs (transcription activator-like effector nucleases) and the CRISPR-Cas (clustered, regularly interspaced short palindromic repeatsCRISPR-associated proteins) system are exciting ${ }^{171,172}$. Although these approaches would be more elegant, their implementation would require tremendous advances in gene delivery, as efficient and effective delivery systems to destroy the viral genomes in rare cells throughout the body are not currently available.

The several approaches to disrupt HIV-1 latency by inducing proviral expression seem to be promising and might be implemented in the foreseeable future. As reactivation of the latent reservoir may be governed by stochastic mechanisms (that is, some latent genomes remain silent even in the event of a single round of maximal mitogen stimulation) ${ }^{138}$, combinatorial latency-reversing therapy that is safe enough to enable multiple administrations may be needed. Ongoing work aims at designing an effective dosing regimen. Potency must be balanced with minimizing toxicity, and the potential impact of any latency-reversing agent on the immune system must be carefully considered. 
In addition, a parallel effort must be made to develop immune-based therapies to ensure and accelerate the process of viral clearance. This effort should be linked to studies of the disruption of latency, as the modalities are likely to be combined. Therefore, given the broad efforts to discover reagents that disrupt latency in resting $\mathrm{T}_{\mathrm{CM}}$ cells as a first step towards viral eradication therapies, systems must be developed to study the interactions between anti-latency approaches that might be used in combination, as well as the interactions between such agents and immunotherapeutic agents that might be used as a potential cure.

The development of approaches to eradicate HIV-1 infection will take time and durable investment in research towards this goal. It is possible that therapies that result in the depletion of persistent infection and the augmentation of the immune response might lead to an intermediate result. Termed by many as a 'functional cure', this is a state in which HIV-1 infection is not cleared but is so tightly controlled by the immune response that the patient is no longer infectious and is clinically stable in the absence of ART. If so, to make such an investment superior to once-a-day ART (or less with the long-acting therapeutic agents that are currently under development), interventions that result in a functional cure would also have to spare patients the chronic immune activation that is seen in natural 'elite controllers' of HIV-1 infection ${ }^{173}$, with its attendant risks of long-term morbidity, as otherwise life-long ART might then be clinically preferable.

The scientific and medical challenges in the effort to eradicate HIV-1 infection are formidable and complex. Ultimately, given the scope of the HIV-1 pandemic, strategies to eradicate the disease must be implemented globally. However, to move the field forwards, early proof-of-concept studies are likely to involve approaches that are not widely feasible; for example, bone marrow transplantation or extremely early HIV-1 treatment may never be practical, but the successes and failures of these approaches can provide valuable insights. Although disappointing, the very recent viral rebound that was observed in the Mississippi baby ${ }^{1}$ after more than 2 years after ART interruption provides valuable clues. Viral rebound after such a long period of time without viraemia in the absence of measurable HIV-1specific immunity suggests, akin to the Boston patients ${ }^{2}$, that individual latently infected cells may remain virologically dormant for a considerable period of time before generating viraemia. The short duration of aviraemia in the Boston patients compared with the longer time off therapy in the Mississippi baby case might simply reflect a lower number of latently infected cells or some immune protection conferred during initial exposure to HIV-1 in the Mississippi baby. Approaches to disrupt latency, or even robustly enforce latency, may succeed if the infected cell population is small enough and durable mechanisms to enhance the HIV-1 immune response are present.

As efforts advance, additional obstacles to clear HIV-1 infection are likely to be uncovered, and careful consideration must be given to the ethics of translational research with otherwise healthy volunteers infected with HIV-1. The recent reinvigoration of efforts to gain a detailed understanding of the biology and pathogenesis of viral latency should give hope that we can overcome these obstacles. The journey towards a cure for HIV/AIDS has begun. 


\section{Acknowledgments}

The authors thank N. Goonetilleke for valuable input. Work in the authors' laboratories was supported by the National Institutes of Health grants AI096113, AI095052 and DA030156 to D.M.M. and AI50410 to the University of North Carolina Center for AIDS research.

\section{Glossary}

\author{
Activated $\mathrm{CD}^{+} \mathrm{T}$ \\ cells
}

HIV-1 reservoirs

\section{Resting memory $\mathrm{CD4}^{+} \mathrm{T}$ cells}

\author{
Latent HIV-1 \\ Two-long terminal \\ repeat circles
}

\section{Homeostatic proliferation \\ Central memory $\mathrm{CD}^{+} \mathrm{T}$ cells}

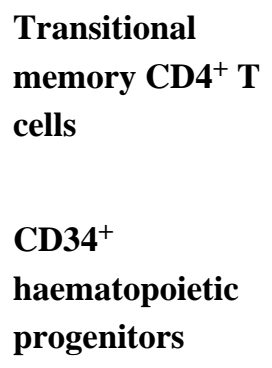

Antigen-specific $\mathrm{CD} 4^{+} \mathrm{T}$ cells that have undergone stimulation of their $\mathrm{T}$ cell receptor-CD3 complexes. Activation of a $\mathrm{T}$ cell increases the surface expression of many proteins, including CD69 and $\mathrm{CD} 25$, and induces functional responses, such as proliferation and cytokine production

Infected cell populations that enable the persistence of replicationcompetent HIV-1 in patients treated with antiretroviral therapy regimens in the order of years. The HIV-1 reservoir comprises both latent HIV-1 infection and other as-yet incompletely defined sources of persistent HIV-1

Antigen-specific $\mathrm{CD} 4^{+} \mathrm{T}$ cells that have reverted to the $\mathrm{G} 0$ state of the cell cycle from a previously activated state but retain the capability to rapidly respond to a second antigenic exposure

Quiescent, replication-competent provirus that exists within a long-lived population of resting cells and that is capable of initiating new rounds of infection if therapy is interrupted

(2-LTR circles). The joining of the two ends of the linear unintegrated HIV-1 DNA (each end having a complete long terminal repeat) into a circularized form of DNA

A physiological process that controls stable and constant cell number without cellular differentiation. Interleukin-7 has a crucial role in maintaining normal $\mathrm{T}$ cell levels

( $\mathrm{T}_{\mathrm{CM}}$ cells). Antigen-specific $\mathrm{CD} 4^{+} \mathrm{T}$ cells that lack immediate effector function but that mediate rapid recall responses and have the capacity to migrate from the blood to the secondary lymphoid organs

( $\mathrm{T}_{\mathrm{TM}}$ cells). Antigen-specific $\mathrm{T}$ cells that transition to the effector memory state and have lost the surface expression of the homing receptor CC-chemokine receptor 7 but retain the expression of the tumour necrosis factor receptor CD27

Human haematopoietic cells that give rise to the myeloid and lymphoid lineages and can be identified by the expression of CD34, CD150 and CD48, but that lack CD244. These cells typically comprise $5 \%$ of the total cell population in the bone marrow 


\section{$\mathrm{CD4}^{+}$memory stem cells}

\author{
Chou-Talalay \\ method
}

( $\mathrm{T}_{\mathrm{SCM}}$ cells). Antigen-specific $\mathrm{T}$ cells with a broadly naive phenotype but with high surface expression of CD95 (also known as Fas ligand), which is a type II transmembrane protein that is expressed at high levels by all memory cells

A method in which a combination index (CI) is used to express the synergy of drugs. A CI $<1$ indicates synergy, a $\mathrm{CI}=1$ suggests an additive effect and a $\mathrm{CI}>1$ is indicative of antagonism

\section{References}

1. Persaud, D. 20th International AIDS Conference. Symposium presentation MOSY0501; International AIDS Society; 2014.

2. Henrich TJ, et al. Antiretroviral-free HIV-1 remission and viral rebound after allogeneic stem cell transplantation: report of 2 cases. Ann Intern Med. 2014; 161:319-327. [PubMed: 25047577]

3. Chun TW, et al. In vivo fate of HIV-1-infected T cells: quantitative analysis of the transition to stable latency. Nature Med. 1995; 1:1284-1290. [PubMed: 7489410]

4. Chun TW, et al. Early establishment of a pool of latently infected, resting CD4 ${ }^{+} \mathrm{T}$ cells during primary HIV-1 infection. Proc Natl Acad Sci USA. 1998; 95:8869-8873. [PubMed: 9671771]

5. Strain MC, et al. Effect of treatment, during primary infection, on establishment and clearance of cellular reservoirs of HIV-1. J Infect Dis. 2005; 191:1410-1418. [PubMed: 15809898]

6. Archin NM, et al. Immediate antiviral therapy appears to restrict resting CD4 ${ }^{+}$cell HIV-1 infection without accelerating the decay of latent infection. Proc Natl Acad Sci USA. 2012; 109:9523-9528. [PubMed: 22645358]

7. Swiggard WJ, et al. Human immunodeficiency virus type 1 can establish latent infection in resting $\mathrm{CD}^{+} \mathrm{T}$ cells in the absence of activating stimuli. J Virol. 2005; 79:14179-14188. [PubMed: 16254353]

8. Bukrinsky MI, Stanwick TL, Dempsey MP, Stevenson M. Quiescent T lymphocytes as an inducible virus reservoir in HIV-1 infection. Science. 1991; 254:423-427. This paper identifies resting T lymphocytes as a major reservoir of HIV-1 infection in which the virus can be reactivated following cell stimulation. [PubMed: 1925601]

9. Zack JA, et al. HIV-1 entry into quiescent primary lymphocytes: molecular analysis reveals a labile, latent viral structure. Cell. 1990; 61:213-222. [PubMed: 2331748]

10. Zhou Y, Zhang H, Siliciano JD, Siliciano RF. Kinetics of human immunodeficiency virus type 1 decay following entry into resting $\mathrm{CD}^{+}{ }^{+} \mathrm{T}$ cells. J Virol. 2005; 79:2199-2210. [PubMed: 15681422]

11. Siliciano JD, et al. Long-term follow-up studies confirm the stability of the latent reservoir for HIV-1 in resting CD4 ${ }^{+}$T cells. Nature Med. 2003; 9:727-728. This study reports that the HIV-1 reservoir is highly stable and decays very slowly in successfully treated patients receiving ART with stably undetectable plasma HIV-1 RNA. [PubMed: 12754504]

12. Calvanese V, Chavez L, Laurent T, Ding S, Verdin E. Dual-color HIV reporters trace a population of latently infected cells and enable their purification. Virology. 2013; 446:283-292. [PubMed: 24074592]

13. Hermankova M, et al. Analysis of human immunodeficiency virus type 1 gene expression in latently infected resting CD4 ${ }^{+}$T lymphocytes in vivo. J Virol. 2003; 77:7383-7392. [PubMed: 12805437]

14. Iglesias-Ussel M, Vandergeeten C, Marchionni L, Chomont N, Romerio F. High levels of CD2 expression identify HIV-1 latently infected resting memory $\mathrm{CD} 4^{+} \mathrm{T}$ cells in virally suppressed subjects. J Virol. 2013; 87:9148-9158. [PubMed: 23760244]

15. Josefsson L, et al. The HIV-1 reservoir in eight patients on long-term suppressive antiretroviral therapy is stable with few genetic changes over time. Proc Natl Acad Sci USA. 2013; 110:25. 
16. Kearney MF, et al. Lack of detectable HIV-1 molecular evolution during suppressive antiretroviral therapy. PLoS Pathog. 2014; 10:e1004010. [PubMed: 24651464]

17. Palmer $S$, et al. Low-level viremia persists for at least 7 years in patients on suppressive antiretroviral therapy. Proc Natl Acad Sci USA. 2008; 105:3879-3884. [PubMed: 18332425]

18. Dornadula G, et al. Residual HIV-1 RNA in blood plasma of patients taking suppressive highly active antiretroviral therapy. JAMA. 1999; 282:1627-1632. [PubMed: 10553788]

19. Grossman Z, et al. Ongoing HIV dissemination during HAART. Nature Med. 1999; 5:1099-1104. [PubMed: 10502799]

20. Frenkel LM, et al. Multiple viral genetic analyses detect low-level human immunodeficiency virus type 1 replication during effective highly active antiretroviral therapy. J Virol. 2003; 77:57215730. [PubMed: 12719565]

21. Buzon MJ, et al. HIV-1 replication and immune dynamics are affected by raltegravir intensification of HAART-suppressed subjects. Nature Med. 2010; 16:460-465. [PubMed: 20228817]

22. Sigal A, et al. Cell-to-cell spread of HIV permits ongoing replication despite antiretroviral therapy. Nature. 2011; 477:95-98. [PubMed: 21849975]

23. Permanyer M, et al. Antiretroviral agents effectively block HIV replication after cell-to-cell transfer. J Virol. 2012; 86:8773-8780. [PubMed: 22696642]

24. Agosto LM, Zhong P, Munro J, Mothes W. Highly active antiretroviral therapies are effective against HIV-1 cell-to-cell transmission. PLoS Pathog. 2014; 10:e1003982. [PubMed: 24586176]

25. Titanji BK, Aasa-Chapman M, Pillay D, Jolly C. Protease inhibitors effectively block cell-to-cell spread of HIV-1 between T cells. Retrovirology. 2013; 10:1742-4690.

26. Yukl SA, et al. Effect of raltegravir-containing intensification on HIV burden and T-cell activation in multiple gut sites of HIV-positive adults on suppressive antiretroviral therapy. AIDS. 2010; 24:2451-2460. [PubMed: 20827162]

27. Vallejo A, et al. The effect of intensification with raltegravir on the HIV-1 reservoir of latently infected memory CD4 T cells in suppressed patients. AIDS. 2012; 26:1885-1894. [PubMed: 22992577]

28. Gandhi RT, et al. No effect of raltegravir intensification on viral replication markers in the blood of HIV-1-infected patients receiving antiretroviral therapy. J Acquir Immune Def Syndr. 2012; 59:229-235.

29. Fletcher CV, et al. Persistent HIV-1 replication is associated with lower antiretroviral drug concentrations in lymphatic tissues. Proc Natl Acad Sci USA. 2014; 111:2307-2312. [PubMed: 24469825]

30. Anton PA, et al. RMP-02/MTN-006: a phase 1 rectal safety, acceptability, pharmacokinetic, and pharmacodynamic study of tenofovir $1 \%$ gel compared with oral tenofovir disoproxil fumarate. AIDS Res Hum Retroviruses. 2012; 28:1412-1421. [PubMed: 22943559]

31. Robbins BL, Nelson SR, Fletcher CV. A novel ultrasensitive LC-MS/MS assay for quantification of intracellular raltegravir in human cell extracts. J Pharm Biomed Anal. 2012; 70:378-387. [PubMed: 22727807]

32. Kieffer TL, et al. Genotypic analysis of HIV-1 drug resistance at the limit of detection: virus production without evolution in treated adults with undetectable HIV loads. J Infect Dis. 2004; 189:1452-1465. [PubMed: 15073683]

33. Bailey JR, et al. Residual human immunodeficiency virus type 1 viremia in some patients on antiretroviral therapy is dominated by a small number of invariant clones rarely found in circulating CD4 ${ }^{+}$T cells. J Virol. 2006; 80:6441-6457. [PubMed: 16775332]

34. Evering TH, et al. Absence of HIV-1 evolution in the gut-associated lymphoid tissue from patients on combination antiviral therapy initiated during primary infection. PLoS Pathog. 2012; 8:e1002506. [PubMed: 22319447]

35. Chomont N, et al. HIV reservoir size and persistence are driven by T cell survival and homeostatic proliferation. Nature Med. 2009; 15:893-900. [PubMed: 19543283]

36. Bosque A, Famiglietti M, Weyrich AS, Goulston C, Planelles V. Homeostatic proliferation fails to efficiently reactivate HIV-1 latently infected central memory CD4 ${ }^{+}$T cells. PLoS Pathog. 2011; $7: 6$. 
37. Maldarelli F, et al. HIV latency. Specific HIV integration sites are linked to clonal expansion and persistence of infected cells. Science. 2014; 345:179-183. [PubMed: 24968937]

38. Wagner TA, et al. HIV latency. Proliferation of cells with HIV integrated into cancer genes contributes to persistent infection. Science. 2014; 345:570-573. References 35 and 38 show that HIV-1 integrates into genes associated with cellular proliferation, which may contribute to aberrant proliferation of silenced HIV-1 genomes. [PubMed: 25011556]

39. Margolis D, Bushman F. HIV/AIDS. Persistence by proliferation? Science. 2014; 345:143-144. [PubMed: 25013050]

40. Lewinski MK, et al. Genome-wide analysis of chromosomal features repressing human immunodeficiency virus transcription. J Virol. 2005; 79:6610-6619. [PubMed: 15890899]

41. Shan L, et al. Influence of host gene transcription level and orientation on HIV-1 latency in a primary-cell model. J Virol. 2011; 85:5384-5393. [PubMed: 21430059]

42. Sherrill-Mix S, et al. HIV latency and integration site placement in five cell-based models. Retrovirology. 2013; 10:1742-4690.

43. Verdin E, Paras P Jr, Van Lint C. Chromatin disruption in the promoter of human immunodeficiency virus type 1 during transcriptional activation. EMBO J. 1993; 12:3249-3259. [PubMed: 8344262]

44. Keedy KS, et al. A limited group of class I histone deacetylases acts to repress human immunodeficiency virus type 1 expression. J Virol. 2009; 83:4749-4756. [PubMed: 19279091]

45. Friedman J, et al. Epigenetic silencing of HIV-1 by the histone H3 lysine 27 methyltransferase enhancer of Zeste 2. J Virol. 2011; 85:9078-9089. [PubMed: 21715480]

46. Mbonye U, Karn J. Transcriptional control of HIV latency: cellular signaling pathways, epigenetics, happenstance and the hope for a cure. Virology. 2014; 454-455:328-339.

47. du Chene I, et al. Suv39H1 and HP1 $\gamma$ are responsible for chromatin-mediated HIV-1 transcriptional silencing and post-integration latency. EMBO J. 2007; 26:424-435. [PubMed: 17245432]

48. Herrmann CH, Rice AP. Lentivirus Tat proteins specifically associate with a cellular protein kinase, TAK, that hyperphosphorylates the carboxyl-terminal domain of the large subunit of RNA polymerase II: candidate for a Tat cofactor. J Virol. 1995; 69:1612-1620. [PubMed: 7853496]

49. Wei P, Garber ME, Fang SM, Fischer WH, Jones KA. A novel CDK9-associated C-type cyclin interacts directly with HIV-1 Tat and mediates its high-affinity, loop-specific binding to TAR RNA. Cell. 1998; 92:451-462. [PubMed: 9491887]

50. Budhiraja S, Famiglietti M, Bosque A, Planelles V, Rice AP. Cyclin T1 and CDK9 T-loop phosphorylation are downregulated during establishment of HIV-1 latency in primary resting memory CD4 ${ }^{+}$T cells. J Virol. 2013; 87:1211-1220. [PubMed: 23152527]

51. Van Lint C, Bouchat S, Marcello A. HIV-1 transcription and latency: an update. Retrovirology. 2013; 10:1742-4690.

52. Descours B, et al. Immune responses driven by protective human leukocyte antigen alleles from long-term nonprogressors are associated with low HIV reservoir in central memory CD4 T cells. Clin Infect Dis. 2012; 54:1495-1503. [PubMed: 22441653]

53. Bacchus C, et al. A single HIV-1 cluster and a skewed immune homeostasis drive the early spread of HIV among resting $\mathrm{CD}^{+}{ }^{+}$cell subsets within one month post-infection. PLoS ONE. 2013; 8:e64219. [PubMed: 23691172]

54. Soriano-Sarabia N, Archin N, Margolis D. Conference on Retroviruses and Opportunistic Infections. 2013:Abstract 46.

55. Zhang J, Crumpacker CS. Hematopoietic stem and progenitor cells in HIV/AIDS and immune reconstitution. Cell Res. 2010; 20:745-747. [PubMed: 20567263]

56. Carter CC, et al. HIV-1 utilizes the CXCR4 chemokine receptor to infect multipotent hematopoietic stem and progenitor cells. Cell Host Microbe. 2011; 9:223-234. [PubMed: 21402361]

57. Carter CC, et al. HIV-1 infects multipotent progenitor cells causing cell death and establishing latent cellular reservoirs. Nature Med. 2010; 16:446-451. [PubMed: 20208541] 
58. Durand CM, et al. HIV-1 DNA is detected in bone marrow populations containing CD4 ${ }^{+} \mathrm{T}$ cells but is not found in purified CD $34^{+}$hematopoietic progenitor cells in most patients on antiretroviral therapy. J Infect Dis. 2012; 205:1014-1018. [PubMed: 22275402]

59. Josefsson L, et al. Hematopoietic precursor cells isolated from patients on long-term suppressive HIV therapy did not contain HIV-1 DNA. J Infect Dis. 2012; 206:28-34. [PubMed: 22536001]

60. Wightman F, et al. Both $\mathrm{CD} 31^{+}$and $\mathrm{CD} 31^{-}$naive $\mathrm{CD} 4^{+} \mathrm{T}$ cells are persistent HIV type 1 -infected reservoirs in individuals receiving antiretroviral therapy. J Infect Dis. 2010; 202:1738-1748. [PubMed: 20979453]

61. Buzon MJ, et al. HIV-1 persistence in $\mathrm{CD}^{+}{ }^{+} \mathrm{T}$ cells with stem cell-like properties. Nature Med. 2014; 20:139-142. [PubMed: 24412925]

62. Cieri N, et al. IL-7 and IL-15 instruct the generation of human memory stem T cells from naive precursors. Blood. 2013; 121:573-584. [PubMed: 23160470]

63. Gattinoni L, et al. A human memory T cell subset with stem cell-like properties. Nature Med. 2011; 17:1290-1297. [PubMed: 21926977]

64. Soriano-Sarabia N, et al. Primary MHC-class $\mathrm{II}^{+}$cells are necessary to promote resting V $\delta 2$ cell expansion in response to $(E)$-4-hydroxy-3-methyl-but-2-enyl-pyrophosphate and isopentenyl pyrophosphate. J Immunol. 2012; 189:5212-5222. [PubMed: 23105138]

65. Morita CT, et al. Structural features of nonpeptide prenyl pyrophosphates that determine their antigenicity for human $\gamma \delta$ T cells. J Immunol. 2001; 167:36-41. [PubMed: 11418629]

66. Hintz M, et al. Identification of (E)-4-hydroxy-3-methyl-but-2-enyl pyrophosphate as a major activator for human $\gamma \delta$ T cells in Escherichia coli. FEBS Lett. 2001; 509:317-322. [PubMed: 11741609]

67. Poupot M, Fournie JJ. Non-peptide antigens activating human $\mathrm{V} \gamma 9 / \mathrm{V} \delta 2 \mathrm{~T}$ lymphocytes. Immunol Lett. 2004; 95:129-138. [PubMed: 15388252]

68. Vavassori S, et al. Butyrophilin 3A1 binds phosphorylated antigens and stimulates human $\gamma \delta \mathrm{T}$ cells. Nature Immunol. 2013; 14:908-916. [PubMed: 23872678]

69. Igarashi T, et al. Macrophage are the principal reservoir and sustain high virus loads in rhesus macaques after the depletion of $\mathrm{CD}^{+} \mathrm{T}$ cells by a highly pathogenic simian immunodeficiency virus/HIV type 1 chimera (SHIV): implications for HIV-1 infections of humans. Proc Natl Acad Sci USA. 2001; 98:658-663. [PubMed: 11136236]

70. Gartner S, et al. The role of mononuclear phagocytes in HTLV-III/LAV infection. Science. 1986; 233:215-219. [PubMed: 3014648]

71. Koenig S, et al. Detection of AIDS virus in macrophages in brain tissue from AIDS patients with encephalopathy. Science. 1986; 233:1089-1093. [PubMed: 3016903]

72. Lambotte O, et al. Detection of infectious HIV in circulating monocytes from patients on prolonged highly active antiretroviral therapy. J Acquir Immune Def Syndr. 2000; 23:114-119.

73. Price RW, et al. The brain in AIDS: central nervous system HIV-1 infection and AIDS dementia complex. Science. 1988; 239:586-592. [PubMed: 3277272]

74. Gorry PR, et al. Diminished production of human immunodeficiency virus type 1 in astrocytes results from inefficient translation of gag, env, and nef mRNAs despite efficient expression of Tat and Rev. J Virol. 1999; 73:352-361. [PubMed: 9847339]

75. Sieweke MH, Allen JE. Beyond stem cells: self-renewal of differentiated macrophages. Science. 2013; 342:1242974. This article reviews recent evidence indicating that, like stem cells, macrophages have self-renewing capabilities. [PubMed: 24264994]

76. Queen SE, et al. Replication-competent simian immunodeficiency virus (SIV) Gag escape mutations archived in latent reservoirs during antiretroviral treatment of SIV-infected macaques. J Virol. 2011; 85:9167-9175. This study determines that SIV Gag escape mutations can be found in the resting $\mathrm{CD}^{+}{ }^{+} \mathrm{T}$ cell latent reservoir in the periphery and the CNS. [PubMed: 21715484]

77. Denton PW, et al. Generation of HIV latency in humanized BLT mice. J Virol. 2012; 86:630-634. This study describes the presence and frequency of replication-competent latent HIV-1 in ARTsuppressed humanized BLT mice. [PubMed: 22013053]

78. Garcia-Martinez, J. HIV Persistence During Therapy, Sixth International Workshop. IHL Press; 2013. p. Abstract 17

79. Margolis DM. How might we cure HIV? Curr Infect Dis Rep. 2014; 16:392. [PubMed: 24562540] 
80. Chun TW, et al. Quantification of latent tissue reservoirs and total body viral load in HIV-1 infection. Nature. 1997; 387:183-188. [PubMed: 9144289]

81. Yang HC, et al. Small-molecule screening using a human primary cell model of HIV latency identifies compounds that reverse latency without cellular activation. J Clin Invest. 2009; 119:3473-3486. [PubMed: 19805909]

82. Cameron PU, et al. Establishment of HIV-1 latency in resting CD4 ${ }^{+} \mathrm{T}$ cells depends on chemokine-induced changes in the actin cytoskeleton. Proc Natl Acad Sci USA. 2010; 107:1693416939. [PubMed: 20837531]

83. Saleh S, et al. CCR7 ligands CCL19 and CCL21 increase permissiveness of resting memory CD4 ${ }^{+}$ T cells to HIV-1 infection: a novel model of HIV-1 latency. Blood. 2007; 110:4161-4164. [PubMed: 17881634]

84. Lassen KG, Hebbeler AM, Bhattacharyya D, Lobritz MA, Greene WC. A flexible model of HIV-1 latency permitting evaluation of many primary CD4 T-cell reservoirs. PLoS ONE. 2012; 7:e30176. [PubMed: 22291913]

85. Jordan A, Bisgrove D, Verdin E. HIV reproducibly establishes a latent infection after acute infection of T cells in vitro. EMBO J. 2003; 22:1868-1877. [PubMed: 12682019]

86. Bosque A, Planelles V. Induction of HIV-1 latency and reactivation in primary memory $\mathrm{CD}^{+}{ }^{+} \mathrm{T}$ cells. Blood. 2009; 113:58-65. [PubMed: 18849485]

87. Bosque A, Planelles V. Studies of HIV-1 latency in an ex vivo model that uses primary central memory T cells. Methods. 2011; 53:54-61. [PubMed: 20970502]

88. Tyagi M, Pearson RJ, Karn J. Establishment of HIV latency in primary CD4 ${ }^{+}$cells is due to epigenetic transcriptional silencing and P-TEFb restriction. J Virol. 2010; 84:6425-6437. [PubMed: 20410271]

89. Spina CA, et al. An in-depth comparison of latent HIV-1 reactivation in multiple cell model systems and resting CD4 ${ }^{+}$T cells from aviremic patients. PLoS Pathog. 2013; 9:e1003834. This study compares the responses to different latency-reactivating stimuli in nearly all of the primary cell HIV-1 latency models that have been described to responses obtained using the QVOA in cells from patients infected with HIV-1. [PubMed: 24385908]

90. Hakre S, Chavez L, Shirakawa K, Verdin E. HIV latency: experimental systems and molecular models. FEMS Microbiol Rev. 2012; 36:706-716. [PubMed: 22372374]

91. Barton KM, Burch BD, Soriano-Sarabia N, Margolis DM. Prospects for treatment of latent HIV. Clin Pharmacol Ther. 2013; 93:46-56. [PubMed: 23212106]

92. Shultz LD, Ishikawa F, Greiner DL. Humanized mice in translational biomedical research. Nature Rev Immunol. 2007; 7:118-130. [PubMed: 17259968]

93. Lan P, Tonomura N, Shimizu A, Wang S, Yang YG. Reconstitution of a functional human immune system in immunodeficient mice through combined human fetal thymus/liver and CD34 ${ }^{+}$cell transplantation. Blood. 2006; 108:487-492. [PubMed: 16410443]

94. Melkus MW, et al. Humanized mice mount specific adaptive and innate immune responses to EBV and TSST-1. Nature Med. 2006; 12:1316-1322. [PubMed: 17057712]

95. Denton PW, et al. Antiretroviral pre-exposure prophylaxis prevents vaginal transmission of HIV-1 in humanized BLT mice. PLoS Med. 2008; 5:e16. [PubMed: 18198941]

96. Brainard DM, et al. Induction of robust cellular and humoral virus-specific adaptive immune responses in human immunodeficiency virus-infected humanized BLT mice. J Virol. 2009; 83:7305-7321. [PubMed: 19420076]

97. Denton PW, et al. Systemic administration of antiretrovirals prior to exposure prevents rectal and intravenous HIV-1 transmission in humanized BLT mice. PLoS ONE. 2010; 5:e8829. [PubMed: 20098623]

98. Marsden MD, et al. HIV latency in the humanized BLT mouse. J Virol. 2012; 86:339-347. [PubMed: 22072769]

99. Long BR, Stoddart CA. a interferon and HIV infection cause activation of human T cells in NSGBLT mice. J Virol. 2012; 86:3327-3336. [PubMed: 22238321]

100. Zou W, et al. Nef functions in BLT mice to enhance HIV-1 replication and deplete CD ${ }^{+} \mathrm{CD} 8^{+}$ thymocytes. Retrovirology. 2012; 9:44. [PubMed: 22640559] 
101. Sun Z, et al. Intrarectal transmission, systemic infection, and CD4 ${ }^{+} \mathrm{T}$ cell depletion in humanized mice infected with HIV-1. J Exp Med. 2007; 204:705-714. [PubMed: 17389241]

102. Denton PW, et al. Targeted cytotoxic therapy kills persisting HIV infected cells during ART. PLoS Pathog. 2014; 10:e1003872. In this study, an immunotoxin is evaluated for its capacity to kill HIV-1-expressing cells in a humanized mouse model. The results show a dramatic reduction in HIV-1 RNA in tissue following immunotoxin administration together with ART. [PubMed: 24415939]

103. Vatakis DN, et al. Using the BLT humanized mouse as a stem cell based gene therapy tumor model. J Vis Exp. 2012; 70:e4181. [PubMed: 23271478]

104. Shimizu S, et al. A highly efficient short hairpin RNA potently down-regulates CCR5 expression in systemic lymphoid organs in the hu-BLT mouse model. Blood. 2010; 115:1534-1544. [PubMed: 20018916]

105. Honeycutt JB, et al. HIV-1 infection, response to treatment and establishment of viral latency in a novel humanized T cell-only mouse (TOM) model. Retrovirology. 2013; 10:121. [PubMed: 24156277]

106. Dinoso JB, et al. A simian immunodeficiency virus-infected macaque model to study viral reservoirs that persist during highly active antiretroviral therapy. J Virol. 2009; 83:9247-9257. This study shows the frequency and distribution of replication-competent latent SIV in ARTsuppressed macaques. [PubMed: 19570871]

107. Clements JE, Gama L, Graham DR, Mankowski JL, Zink MC. A simian immunodeficiency virus macaque model of highly active antiretroviral treatment: viral latency in the periphery and the central nervous system. Curr Opin HIV AIDS. 2011; 6:37-42. [PubMed: 21242892]

108. Hirsch VM, Zack PM, Vogel AP, Johnson PR. Simian immunodeficiency virus infection of macaques: end-stage disease is characterized by widespread distribution of proviral DNA in tissues. J Infect Dis. 1991; 163:976-988. [PubMed: 2019773]

109. Horiike M, et al. Lymph nodes harbor viral reservoirs that cause rebound of plasma viremia in SIV-infected macaques upon cessation of combined antiretroviral therapy. Virology. 2012; 423:107-118. [PubMed: 22196013]

110. Baskin GB, et al. Distribution of SIV in lymph nodes of serially sacrificed rhesus monkeys. AIDS Res Hum Retroviruses. 1995; 11:273-285. [PubMed: 7742041]

111. Shen A, et al. Resting CD4 ${ }^{+} \mathrm{T}$ lymphocytes but not thymocytes provide a latent viral reservoir in a simian immunodeficiency virus-Macaca nemestrina model of human immunodeficiency virus type 1-infected patients on highly active antiretroviral therapy. J Virol. 2003; 77:4938-4949. [PubMed: 12663799]

112. Clements JE, et al. The central nervous system as a reservoir for simian immunodeficiency virus (SIV): steady-state levels of SIV DNA in brain from acute through asymptomatic infection. J Infect Dis. 2002; 186:905-913. [PubMed: 12232830]

113. Clements JE, et al. The central nervous system is a viral reservoir in simian immunodeficiency virus-infected macaques on combined antiretroviral therapy: a model for human immunodeficiency virus patients on highly active antiretroviral therapy. J Neurovirol. 2005; 11:180-189. [PubMed: 16036796]

114. Zink MC, et al. Simian immunodeficiency virus-infected macaques treated with highly active antiretroviral therapy have reduced central nervous system viral replication and inflammation but persistence of viral DNA. J Infect Dis. 2010; 202:161-170. [PubMed: 20497048]

115. Van Rompay KK. Evaluation of antiretrovirals in animal models of HIV infection. Antiviral Res. 2010; 85:159-175. [PubMed: 19622373]

116. Deere JD, et al. Analysis of multiply spliced transcripts in lymphoid tissue reservoirs of rhesus macaques infected with RT-SHIV during HAART. PLoS ONE. 2014; 9:e87914. [PubMed: 24505331]

117. North TW, et al. Viral sanctuaries during highly active antiretroviral therapy in a nonhuman primate model for AIDS. J Virol. 2010; 84:2913-2922. [PubMed: 20032180]

118. Schmitz JE, et al. Control of viremia in simian immunodeficiency virus infection by CD8 ${ }^{+}$ lymphocytes. Science. 1999; 283:857-860. [PubMed: 9933172] 
119. Hansen SG, et al. Cytomegalovirus vectors violate $\mathrm{CD}^{+} \mathrm{T}$ cell epitope recognition paradigms. Science. 2013; 340:1237874. [PubMed: 23704576]

120. Hansen SG, et al. Immune clearance of highly pathogenic SIV infection. Nature. 2013; 502:100 104. [PubMed: 24025770]

121. Mavigner M, et al. Special issue: abstracts from the 2014 conference on retroviruses and opportunistic infections. Top Antivir Med. 2014:Abstract 416.

122. Kiem HP, et al. Special issue: abstracts from the 2014 conference on retroviruses and opportunistic infections. Top Antivir Med. 2014:Abstract 419.

123. Spivak AM, et al. A pilot study assessing the safety and latency-reversing activity of disulfiram in HIV-1-infected adults on antiretroviral therapy. Clin Infect Dis. 2014; 58:883-890. [PubMed: 24336828]

124. Prins JM, et al. Immuno-activation with anti-CD3 and recombinant human IL-2 in HIV-1-infected patients on potent antiretroviral therapy. AIDS. 1999; 13:2405-2410. [PubMed: 10597782]

125. Archin NM, et al. Expression of latent HIV induced by the potent HDAC inhibitor suberoylanilide hydroxamic acid. AIDS Res Hum Retroviruses. 2009; 25:207-212. [PubMed: 19239360]

126. Contreras X, et al. Suberoylanilide hydroxamic acid reactivates HIV from latently infected cells. J Biol Chem. 2009; 284:6782-6789. [PubMed: 19136668]

127. Kauder SE, Bosque A, Lindqvist A, Planelles V, Verdin E. Epigenetic regulation of HIV-1 latency by cytosine methylation. PLoS Pathog. 2009; 5:e1000495. [PubMed: 19557157]

128. Blazkova J, et al. CpG methylation controls reactivation of HIV from latency. PLoS Pathog. 2009; 5:e1000554. [PubMed: 19696893]

129. Bullen CK, Laird GM, Durand CM, Siliciano JD, Siliciano RF. New ex vivo approaches distinguish effective and ineffective single agents for reversing HIV-1 latency in vivo. Nature Med. 2014; 20:425-429. [PubMed: 24658076]

130. Archin NM, et al. Administration of vorinostat disrupts HIV-1 latency in patients on antiretroviral therapy. Nature. 2012; 487:482-485. [PubMed: 22837004]

131. Shirakawa K, Chavez L, Hakre S, Calvanese V, Verdin E. Reactivation of latent HIV by histone deacetylase inhibitors. Trends Microbiol. 2013; 21:277-285. [PubMed: 23517573]

132. Rasmussen T. Special issue: abstracts from the 2014 conference on retroviruses and opportunistic infections. Top Antivir Med. 2014; 22:e-1 Abstract 438LB.

133. Elliot J, et al. Highlights of the 20th conference on retroviruses and opportunistic infections. Top Antivir Med. 2013; 21:Abstract 50LB.

134. Wei DG, et al. Histone deacetylase inhibitor romidepsin induces HIV expression in CD4 T cells from patients on suppressive antiretroviral therapy at concentrations achieved by clinical dosing. PLoS Pathog. 2014; 10:e1004071. This study characterizes the ability of the HDAC inhibitor romidepsin to induce HIV-1 expression in vitro in $\mathrm{CD}^{+}{ }^{+} \mathrm{T}$ cells isolated from aviraemic patients infected with HIV-1. [PubMed: 24722454]

135. Archin NM, et al. HIV-1 expression within resting CD4 T-cells following multiple doses of vorinostat. J Infect Dis. 2014; 210:728-735. [PubMed: 24620025]

136. Yang K, et al. Special issue: abstracts from the 2014 conference on retroviruses and opportunistic infections. Top Antivir Med. 2014; 22 :e-1 Abstract 435.

137. Graf EH, et al. Gag-positive reservoir cells are susceptible to HIV-specific cytotoxic T lymphocyte mediated clearance. PLoS ONE. 2013; 8:e71879. [PubMed: 23951263]

138. Ho YC, et al. Replication-competent noninduced proviruses in the latent reservoir increase barrier to HIV-1 cure. Cell. 2013; 155:540-551. This study reports that, although $~ 90 \%$ of non-induced proviruses in the QVOA are defective, $\sim 11.7 \%$ of these non-induced proviruses have intact genomes, which suggests that the QVOA may underestimate the true size of the latent reservoir in some patients. [PubMed: 24243014]

139. Burnett JC, et al. Combinatorial latency reactivation for HIV-1 subtypes and variants. J Virol. 2010; 84:5958-5974. [PubMed: 20357084]

140. Reuse S, et al. Synergistic activation of HIV-1 expression by deacetylase inhibitors and prostratin: implications for treatment of latent infection. PLoS ONE. 2009; 4:0006093. 
141. Bernhard W, et al. The Suv39H1 methyltransferase inhibitor chaetocin causes induction of integrated HIV-1 without producing a T cell response. FEBS Lett. 2011; 585:3549-3554. [PubMed: 22020221]

142. Fernandez G, Zeichner SL. Cell line-dependent variability in HIV activation employing DNMT inhibitors. Virol J. 2010; 7:266. [PubMed: 20942961]

143. Chou TC. Drug combination studies and their synergy quantification using the Chou-Talalay method. Cancer Res. 2010; 70:440-446. [PubMed: 20068163]

144. Shan L, et al. Stimulation of HIV-1-specific cytolytic T lymphocytes facilitates elimination of latent viral reservoir after virus reactivation. Immunity. 2012; 36:491-501. This study found that reversal of HIV-1 latency did not result in uniform cell clearance in an in vitro model system and shows that stimulation of CTLs with HIV-1 peptides improves the recognition and killing of infected cells in vitro. [PubMed: 22406268]

145. Khaitan A, Unutmaz D. Revisiting immune exhaustion during HIV infection. Curr HIV/AIDS Rep. 2011; 8:4-11. [PubMed: 21188556]

146. Moir S, et al. Evidence for HIV-associated B cell exhaustion in a dysfunctional memory B cell compartment in HIV-infected viremic individuals. J Exp Med. 2008; 205:1797-1805. [PubMed: 18625747]

147. Goulder PJ, Watkins DI. HIV and SIV CTL escape: implications for vaccine design. Nature Rev Immunol. 2004; 4:630-640. [PubMed: 15286729]

148. Papuchon J, et al. Resistance mutations and CTL epitopes in archived HIV-1 DNA of patients on antiviral treatment: toward a new concept of vaccine. PLoS ONE. 2013; 8:e69029. [PubMed: 23874854]

149. Garcia F, Leon A, Gatell JM, Plana M, Gallart T. Therapeutic vaccines against HIV infection. Hum Vaccin Immunother. 2012; 8:569-581. This review summarizes the different types of HIV-1 vaccines that have been developed so far, highlighting the main characteristics of each and clinical trials when applicable. [PubMed: 22634436]

150. Gay C, et al. Special issue: abstracts from the 2014 conference on retroviruses and opportunistic infections. Top Antivir Med. 2014; 22:e-1 Abstract 344.

151. Casazza JP, et al. Therapeutic vaccination expands and improves the function of the HIV-specific memory T-cell repertoire. J Infect Dis. 2013; 207:1829-1840. [PubMed: 23482645]

152. Chapuis AG, et al. HIV-specific $\mathrm{CD}^{+} \mathrm{T}$ cells from $\mathrm{HIV}^{+}$individuals receiving HAART can be expanded ex vivo to augment systemic and mucosal immunity in vivo. Blood. 2011; 117:53915402. [PubMed: 21422474]

153. Sung, J., et al. Sixth International Workshop on HIV Persistence during Therapy. IHL Press; 2013. Abstract 58

154. Vivier E, et al. Innate or adaptive immunity? The example of natural killer cells. Science. 2011; 331:44-49. [PubMed: 21212348]

155. Groscurth P. Cytotoxic effector cells of the immune system. Anat Embryol. 1989; 180:109-119. [PubMed: 2679226]

156. Hudspeth K, et al. Engagement of NKp30 on V $81 \mathrm{~T}$ cells induces the production of CCL3, CCL4, and CCL5 and suppresses HIV-1 replication. Blood. 2012; 119:4013-4016. [PubMed: 22403253]

157. Terme M, Ullrich E, Delahaye NF, Chaput N, Zitvogel L. Natural killer cell-directed therapies: moving from unexpected results to successful strategies. Nature Immunol. 2008; 9:486-494. [PubMed: 18425105]

158. Steel JC, Waldmann TA, Morris JC. Interleukin-15 biology and its therapeutic implications in cancer. Trends Pharmacol Sci. 2012; 33:35-41. [PubMed: 22032984]

159. Wiernik A, et al. Targeting natural killer cells to acute myeloid leukemia in vitro with a CD16 $\mathrm{x}$ 33 bispecific killer cell engager and ADAM17 inhibition. Clin Cancer Res. 2013; 19:3844-3855. [PubMed: 23690482]

160. Bonsignori M, et al. Antibody-dependent cellular cytotoxicity-mediating antibodies from an HIV-1 vaccine efficacy trial target multiple epitopes and preferentially use the VH1 gene family. J Virol. 2012; 86:11521-11532. [PubMed: 22896626]

161. Porter DL, Levine BL, Kalos M, Bagg A, June CH. Chimeric antigen receptor-modified T cells in chronic lymphoid leukemia. N Engl J Med. 2011; 365:725-733. [PubMed: 21830940] 
162. Varela-Rohena A, et al. Control of HIV-1 immune escape by CD8 T cells expressing enhanced Tcell receptor. Nature Med. 2008; 14:1390-1395. In this study, T cells were engineered to recognize HIV-1 strains that have evaded the immune system. [PubMed: 18997777]

163. Heslop HE. Genetic engineering of T-cell receptors: TCR takes to titin. Blood. 2013; 122:853854. [PubMed: 23929832]

164. Day CL, et al. PD-1 expression on HIV-specific T cells is associated with T-cell exhaustion and disease progression. Nature. 2006; 443:350-354. [PubMed: 16921384]

165. Leng Q, Bentwich Z, Magen E, Kalinkovich A, Borkow G. CTLA-4 upregulation during HIV infection: association with anergy and possible target for therapeutic intervention. AIDS. 2002; 16:519-529. [PubMed: 11872994]

166. Palmer BE, et al. In vivo blockade of the PD-1 receptor suppresses HIV-1 viral loads and improves $\mathrm{CD}^{+}{ }^{+} \mathrm{T}$ cell levels in humanized mice. J Immunol. 2013; 190:211-219. [PubMed: 23209326]

167. Pincus SH. Therapeutic potential of anti-HIV immunotoxins. Antiviral Res. 1996; 33:1-9. [PubMed: 8955848]

168. Davey RT Jr, et al. Use of recombinant soluble CD4 Pseudomonas exotoxin, a novel immunotoxin, for treatment of persons infected with human immunodeficiency virus. J Infect Dis. 1994; 170:1180-1188. [PubMed: 7963711]

169. Bera TK, et al. Specific killing of HIV-infected lymphocytes by a recombinant immunotoxin directed against the HIV-1 envelope glycoprotein. Mol Med. 1998; 4:384-391. [PubMed: 10780881]

170. Dadachova E, et al. Targeted killing of virally infected cells by radiolabeled antibodies to viral proteins. PLoS Med. 2006; 3:e427. [PubMed: 17090209]

171. Tebas P, et al. Gene editing of CCR5 in autologous CD4 T cells of persons infected with HIV. N Engl J Med. 2014; 370:901-910. [PubMed: 24597865]

172. Gaj T, Gersbach CA, Barbas CF 3rd. ZFN, TALEN, and CRISPR/Cas-based methods for genome engineering. Trends Biotechnol. 2013; 31:397-405. [PubMed: 23664777]

173. Hatano H, et al. Prospective antiretroviral treatment of asymptomatic, HIV-1 infected controllers. PLoS Pathog. 2013; 9:10.

174. Myers LE, McQuay LJ, Hollinger FB. Dilution assay statistics. J Clin Microbiol. 1994; 32:732739. [PubMed: 8195386]

175. Siliciano JD, Siliciano RF. Enhanced culture assay for detection and quantitation of latently infected, resting CD4 ${ }^{+}$T-cells carrying replication-competent virus in HIV-1-infected individuals. Methods Mol Biol. 2005; 304:3-15. [PubMed: 16061962]

176. Archin NM, et al. Special issue: abstracts from the 2014 conference on retroviruses and opportunistic infections. Top Antivir Med. 2014; 22:e-1 Abstract 406.

177. Rouzioux C, Richman D. How to best measure HIV reservoirs? Curr Opin HIV AIDS. 2013; 8:170-175. [PubMed: 23564004]

178. Pasternak AO, Lukashov VV, Berkhout B. Cell-associated HIV RNA: a dynamic biomarker of viral persistence. Retrovirology. 2013; 10:1742-4690.

179. Palmer S, et al. New real-time reverse transcriptase-initiated PCR assay with single-copy sensitivity for human immunodeficiency virus type 1 RNA in plasma. J Clin Microbiol. 2003; 41:4531-4536. [PubMed: 14532178]

180. Strain MC, Richman DD. New assays for monitoring residual HIV burden in effectively treated individuals. Curr Opin HIV AIDS. 2013; 8:106-110. [PubMed: 23314907]

181. Strain MC, et al. Highly precise measurement of HIV DNA by droplet digital PCR. PLoS ONE. 2013; 8:e55943. This paper demonstrates the ability of droplet digital PCR to reliably and accurately measure the frequency of total HIV-1 DNA and episomal 2-LTR circles in cells isolated from patients infected with HIV-1. [PubMed: 23573183]

182. Kiselinova M, et al. Comparison of droplet digital PCR and seminested real-time PCR for quantification of cell-associated HIV-1 RNA. PLoS ONE. 2014; 9:e85999. This paper reports the feasibility of using droplet digital PCR to measure cell-associated RNA from patients infected with HIV-1. [PubMed: 24465831] 
183. Sanchez G, Xu X, Chermann JC, Hirsch I. Accumulation of defective viral genomes in peripheral blood mononuclear cells of human immunodeficiency virus type 1-infected individuals. J Virol. 1997; 71:2233-2240. [PubMed: 9032358]

184. Kieffer TL, et al. $\mathrm{G} \rightarrow \mathrm{A}$ hypermutation in protease and reverse transcriptase regions of human immunodeficiency virus type 1 residing in resting CD4 ${ }^{+}$T cells in vivo. J Virol. 2005; 79:19751980. [PubMed: 15650227]

185. Eriksson S, et al. Comparative analysis of measures of viral reservoirs in HIV-1 eradication studies. PLoS Pathog. 2013; 9:e1003174. [PubMed: 23459007]

186. Anderson JA, et al. Clonal sequences recovered from plasma from patients with residual HIV-1 viremia and on intensified antiretroviral therapy are identical to replicating viral RNAs recovered from circulating resting CD4 ${ }^{+}$T cells. J Virol. 2011; 85:5220-5223. [PubMed: 21367910]

187. Soriano-Sarabia, N., et al. The quantitation of replication-competent HIV-1 in populations of resting CD4 ${ }^{+}$T cells. J Virol. 2014. http://dx.doi.org/10.1128/JVI.01900-14 


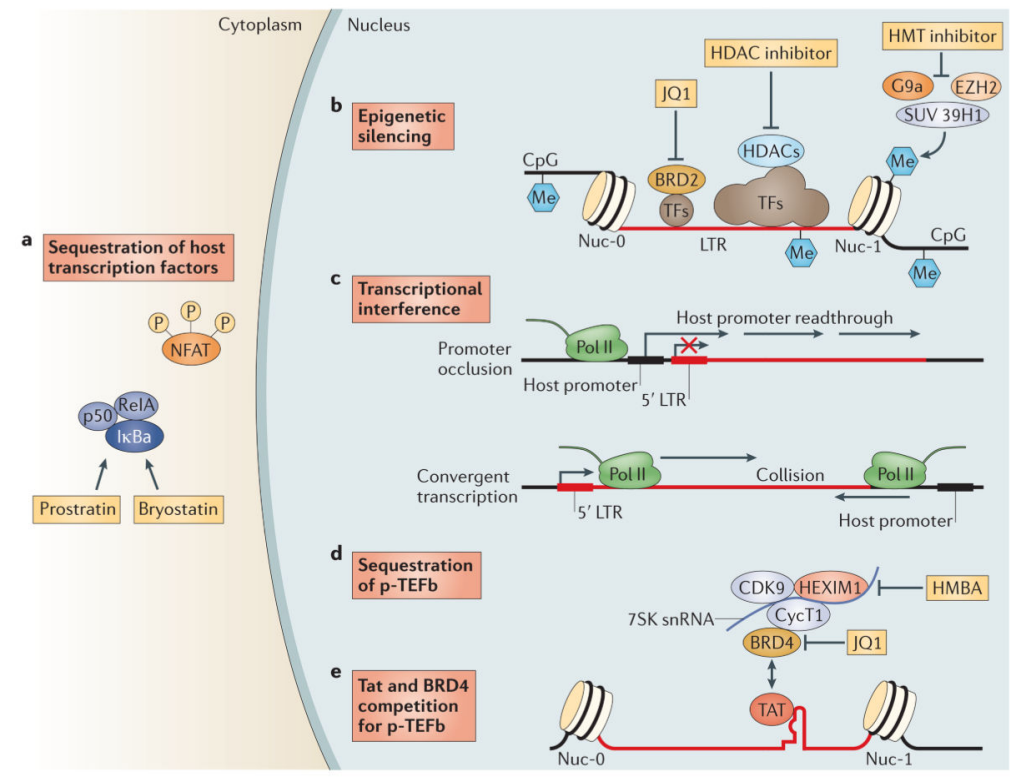

Figure 1. Mechanisms involved in the maintenance of HIV-1 latency and strategies to disrupt latency

HIV-1 latency is maintained by several mechanisms. a $\mid$ Transcription factors (TFs), including nuclear factor- $\kappa \mathrm{B}(\mathrm{NF}-\kappa \mathrm{B})$ and nuclear factor of activated $\mathrm{T}$ cells (NFAT), are sequestered in the cytoplasm, which leads to transcriptional silencing. Bryostatin and prostratin induce activation of $\mathrm{NF}-\kappa \mathrm{B}$, leading to its translocation to the nucleus where it activates HIV-1 transcription. b | The HIV-1 long terminal repeat (LTR) is flanked by the Nuc-0 and Nuc-1 nucleosomes that, when latent, can encode repressive post-translational histone modifications. Histone deacetylases (HDACs), which are recruited by transcription factors (such as YY1 and CBF-1), remove the acetyl groups from chromatin. Histone methyltransferases (HMTs), such as SUV39H1, G9a and EZH2, deposit methyl groups onto histones. HDACs and HMTs enforce the repressive state. Both HDAC inhibitors and HMT inhibitors can induce transcription from quiescent LTR promoters. HIV-1 DNA can also be methylated, although recent evidence suggests that DNA methylation is an epiphenomenon that does not play a part in HIV-1 latency. Bromodomain-containing (BRD) proteins have a complex role in HIV-1 transcription initiation and processivity. Recent evidence suggests that BRD2 has a unique role in enforcing HIV-1 latency, and therefore, BRD inhibitors such as JQ1 may be of use as latency-reversing agents. $\mathbf{c}$ Transcriptional interference may contribute to the regulation of HIV-1 latency. If viral DNA is integrated within an intron of an upstream host gene, readthrough of RNA polymerase II (Pol II) displaces key transcription factors on the HIV-1 LTR (known as promoter occlusion). Conversely, if the viral genome is integrated in the opposite polarity relative to the host gene, host RNA Pol II complexes may induce premature termination of HIV-1 transcription (known as convergent transcription). d,e $\mid$ The positive transcription elongation factor $b$ ( $\mathrm{p}$-TEFb) complex (which comprises CDK9 and cyclin T1 (CycT1)) is sequestered in an inactive ribonucleoprotein complex with HEXIM1-7SK small nuclear RNA (snRNA). BRD4 may compete with the viral Tat activator for binding to $\mathrm{p}$-TEFb. Hexamethylene bisacetamide (HMBA) releases $\mathrm{p}$ TEFb from the HEXIM1-7SK snRNA inhibitory complex and the small-molecule inhibitor JQ1 may antagonize BRD4, both of which enable induction of latent HIV-1 expression. 
a

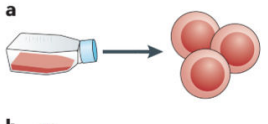

b

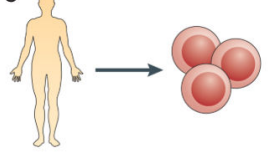

c

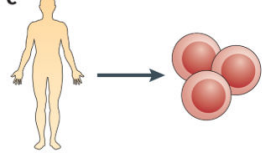

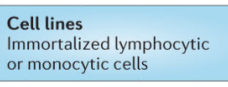

or monocytic cells
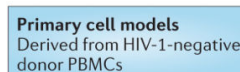

donor PBMCs

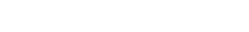

Resting CD4 cells

Derived from HIV-1 positive patients

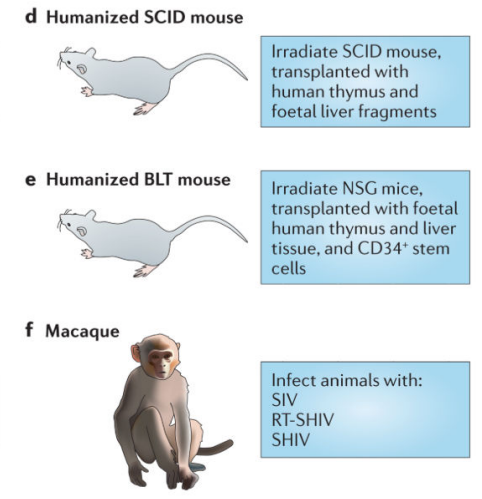

Figure 2. Current model systems to study HIV-1 latency

$\mathbf{a}-\mathbf{c} \mid$ Cell models. Cell line models (part a) are derived from immortalized $\mathrm{T}$ cell clones (for example, from Jurkat-derived cell lines) or promonocyte clones (for example, U1), and they have uniformly integrated copies of proviral HIV-1 DNA. By contrast, primary cell models (part b) are derived from HIV-1-negative donor $\mathrm{CD}^{+} \mathrm{T}$ cells, and latency is established following infection using different protocols. Studies in cells obtained from aviraemic, antiretroviral therapy (ART)-treated patients (part c) can be studied ex vivo for their response to putative latency-reversing agents and other stimuli. d,e $\mid$ Humanized mouse models. Several humanized mouse models have been developed by engraftment of mice with various human tissues. Humanized severe combined immunodeficiency (SCID) mice (part d) are generated by transplanting irradiated SCID mice with human thymus and foetal liver tissue that develops into a human thymic organoid and supports HIV-1 infection, but only within this organoid. As HIV-1 replication is limited to the thymus, latency is only established in naive T cells. Engraftment of the human immune system was vastly improved with the development of the humanized NSG (NOD SCID gamma) mouse (not shown), which is generated by transplanting irradiated NOD/SCID/IL-2R $\gamma$ chain knockout mice with human $\mathrm{CD} 4^{+}$stem cells. Humanized BLT (bone marrow-liver-thymus) mice are generated by implanting human foetal thymus and liver cells into NOD SCID or NSG mice and transplantation of human $\mathrm{CD} 34^{+}$stem cells (part $\mathbf{e}$ ). The reconstitution of the human immune system and the systemic modelling of HIV infection and latency is most robust in this mouse model. $\mathbf{f} \mid$ Non-human primate models. SIV infection in rhesus and pig-tailed macaques is similar to the progression of HIV-1 infection in humans. When susceptible, SIV-infected animals respond to ART. However, SIV is not susceptible to non-nucleoside reverse transcriptase inhibitors (NNRTIs) and its envelope sequence is functionally divergent from that of HIV-1. The recombinant SIV viruses RT-SHIV and SHIV are aimed at overcoming these limitations using HIV-1 reverse transcriptase and envelope, respectively. RT-SHIV enables the use of clinically relevant ART combinations, and SHIV models have wider immunotherapeutic potential and can use both CC-chemokine receptor 5 (CCR5) and CXC-chemokine receptor 4 (CXCR4) co-receptors. PBMCs, peripheral blood mononuclear cells. 

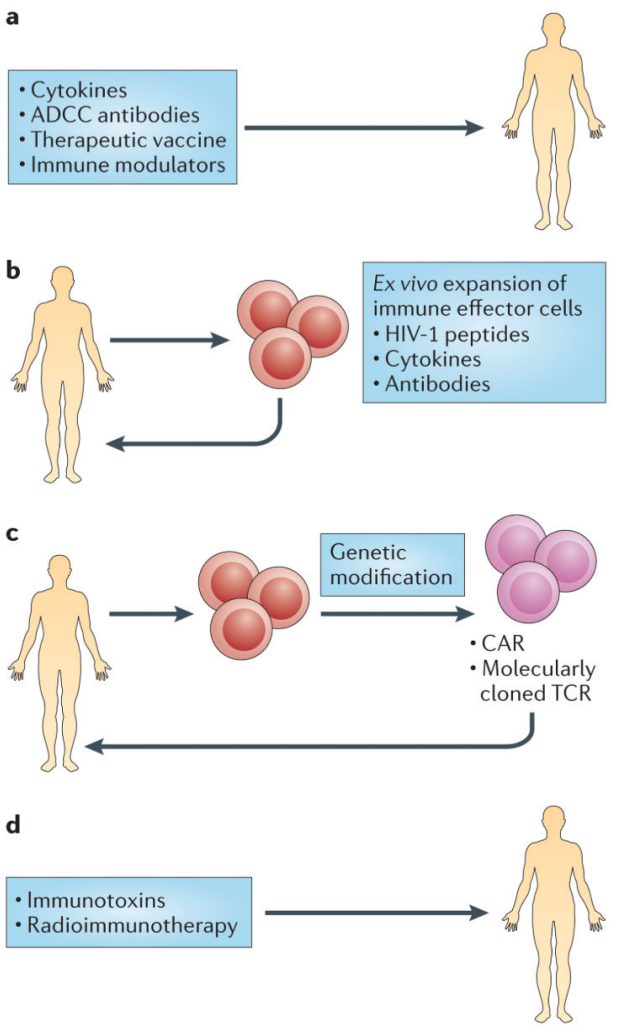

Figure 3. Strategies to eliminate latently infected cells

The induction of latent proviral expression and ensuing viral cytopathic effects may not be sufficient to clear latently infected cells. An effective eradication strategy is likely to require interventions to enhance the HIV-1-specific immune response. Approaches include in vivo administration of molecules that improve immune function and the ex vivo stimulation of cells that have been isolated from patients infected with HIV-1. a In vivo administration of cytokines, antibodies, inhibitors of the PD-1 pathway or components of a therapeutic vaccine present a promising potential therapeutic intervention for enhancing immune responses or reversing immune exhaustion. b | Another potential strategy involves ex vivo priming of immune effectors for optimal function. Specific cell populations isolated from infected individuals, such as cytotoxic T lymphocytes (CTLs), natural killer cells or $\gamma \delta \mathrm{T}$ cells, are stimulated with cytokines, antibodies or HIV-1 peptides and are subsequently reinfused. c| Patient-derived effector cells can also be genetically engineered to increase their efficiency and redirect them to the desired targets. Peripheral blood cells that have been isolated from patients can be genetically modified with a molecularly cloned $\mathrm{T}$ cell receptor (TCR) that redirects cells to viral antigens, and T cells can be modified to express chimeric antigen receptors (CARs) with improved antigen specificity. d | Immunotoxins that consist of a targeting portion, such as an antibody or a ligand, and a toxin effector domain can be administered in vivo for targeted killing of virally infected cells. Radiolabelled antibodies that target HIV-1 proteins could deplete chronically HIV-1-infected cells. ADCC, antibodydependent cellular cytotoxicity. 


\section{New infection}

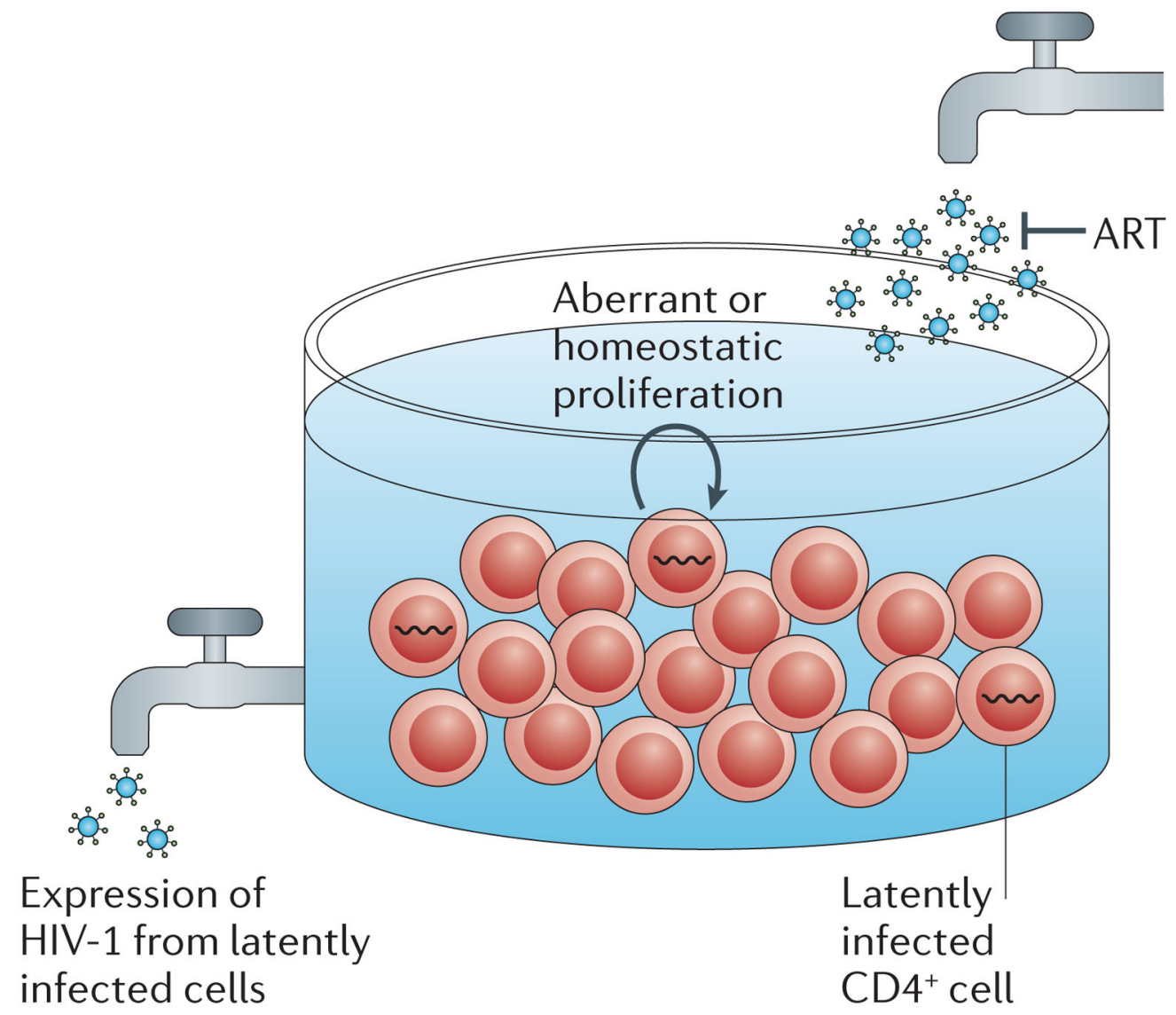

Figure 4. Barriers to HIV-1 eradication

The frequency of latently infected, resting central memory $\mathrm{CD} 4^{+} \mathrm{T}$ cells is stable in patients despite years of antiretroviral therapy (ART). Therefore, the rate of creation of these cells must closely match their rate of destruction. Although the frequency of such infected cells is proportional to the exposure to viraemia over time during initial, acute infection, the initiation of ART seems to completely block the generation of latently infected cells via new infection. As low-level viraemia seems to originate, at least in part, from the expression of virus within the latently infected central memory $\mathrm{CD}^{+}{ }^{+} \mathrm{T}$ cell pool ${ }^{33,186}$, this latent reservoir must be maintained by one or more mechanisms, such as: new infection at extremely low frequency; the ability of some cells to resist death or clearance despite virion production; or the homeostatic or aberrant proliferation of a proportion of the cell pool without virion production and/or cell clearance. 


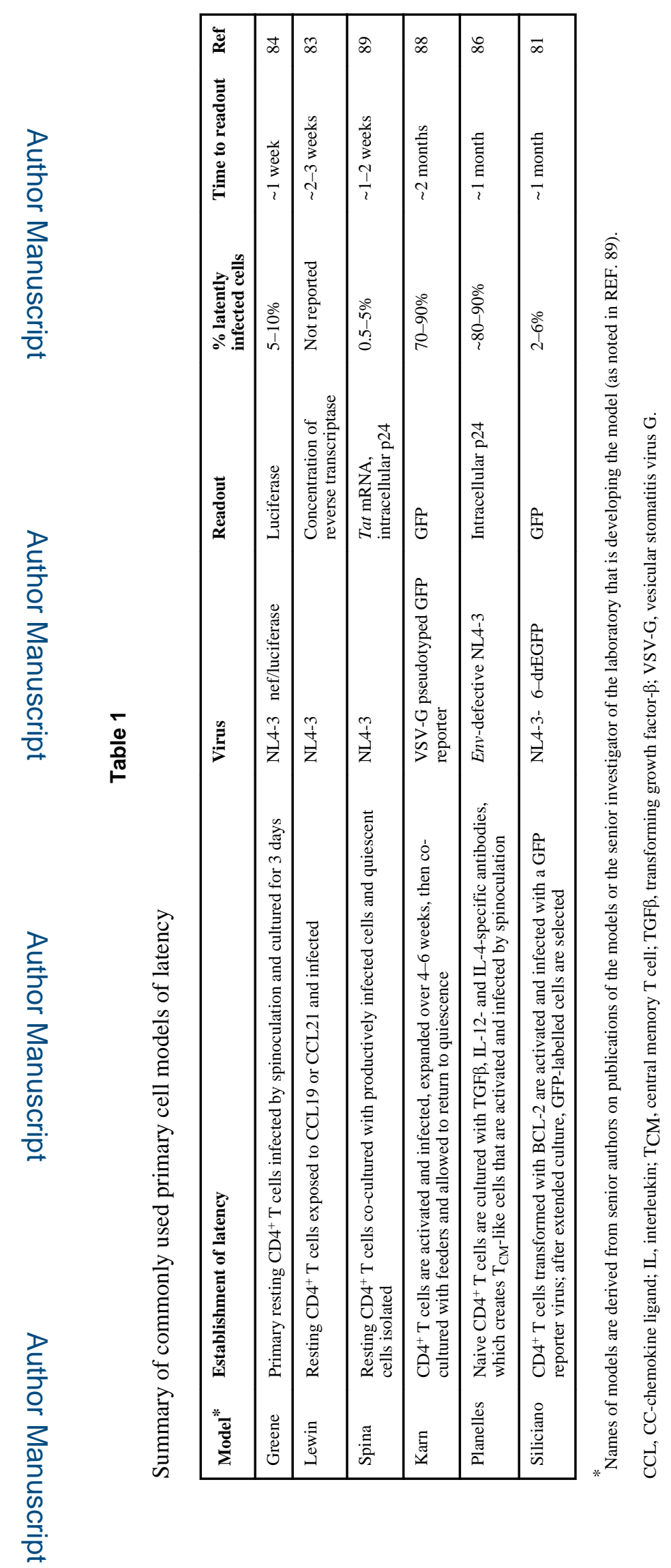

Nat Rev Microbiol. Author manuscript; available in PMC 2015 November 01. 
Table 2

Ongoing or recently completed clinical trials to disrupt HIV-1 latency

\begin{tabular}{|c|c|c|c|}
\hline $\begin{array}{l}\text { Mechanism to } \\
\text { disrupt latency }\end{array}$ & Compound & Clinical trials ${ }^{*}$ & Comments \\
\hline PTEN inhibitor & Disulfiram & $\begin{array}{l}\text { Short-term disulfiram administration to accelerate } \\
\text { the decay of the HIV-1 reservoir in antiretroviral- } \\
\text { treated HIV-1 infected individuals } \\
(\underline{\text { NCT01286259) }}\end{array}$ & $\begin{array}{l}\text { Completed: a transient increase in } \\
\text { single-copy assay viraemia was } \\
\text { observed in six patients at different } \\
\text { times after disulfiram dosing; however, } \\
\text { the size of the HIV-1 latent reservoir } \\
\text { remained unaffected }^{123}\end{array}$ \\
\hline HDAC inhibitor & Romidepsin & $\begin{array}{l}\text { Evaluating the safety and efficacy of single-dose } \\
\text { romidepsin in combination with antiretroviral } \\
\text { therapy in HIV-1-infected adults with suppressed } \\
\text { viral load (NCT01933594) }\end{array}$ & Enrolling \\
\hline HDAC inhibitor & Romidepsin & $\begin{array}{l}\text { Safety and efficacy of romidepsin and the } \\
\text { therapeutic vaccine vacc-4x for reduction of the } \\
\text { latent HIV-1 reservoir (REDUC; NCT02092116) }\end{array}$ & Ongoing \\
\hline HDAC inhibitor & Panobinostat (Novartis) & $\begin{array}{l}\text { Safety and effect of panobinostat on HIV-1 } \\
\text { expression in patients on suppressive HAART } \\
\text { (CLEAR; NCT01680094) }\end{array}$ & $\begin{array}{l}\text { Completed: a } 2.1-14.4 \text {-fold increase in } \\
\text { cell-associated RNA was observed in all } \\
\text { patients and remained increased } 4 \\
\text { weeks after panobinostat } \\
\text { administration; however, no change in } \\
\text { integrated HIV-1 DNA was observed }{ }^{132}\end{array}$ \\
\hline HDAC inhibitor & Vorinostat & 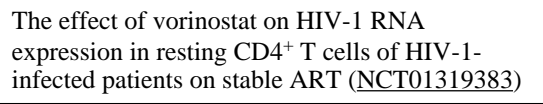 & Enrolling \\
\hline HDAC inhibitor & Vorinostat & $\begin{array}{l}\text { A pilot study to assess the safety and effect of } \\
\text { vorinostat on HIV-1 transcription in patients } \\
\text { receiving suppressive combination anti-retroviral } \\
\text { therapy (NCT01365065) }\end{array}$ & $\begin{array}{l}\text { Completed: a significant increase in } \\
\text { cell-associated RNA was observed in } \\
88 \% \text { of patients during vorinostat } \\
\text { dosing; no significant change in DNA } \\
\text { was observed }^{133}\end{array}$ \\
\hline
\end{tabular}

The clinicaltrials.gov identifier is given in brackets.

ART, antiretroviral therapy; HAART, highly active ART; HDAC, histone deacetylase; PTEN, phosphatase and tensin homologue. 